\title{
Avaliação da eficiência hidrológica por meio da implantação de técnicas compensatórias em loteamento urbano
}

\section{Evaluation of hydrological efficiency by the implantation of best management practices in residential neighborhood}

Data de entrada: 02/06/2019

Data de aprovação: 07/11/2019

Frederico Carlos Martins de Menezes Filho ${ }^{1 *}$ | João Marcos da Silva Araújo ${ }^{1}$

DOI: https://doi.org/10.36659/dae.2021.003

ORCID ID

Menezes Filho FCM (D) https://orcid.org/0000-0003-4874-0254

Araújo JMS (D) https://orcid.org/0000-0002-1157-8102

\section{Resumo}

Diante do atual cenário de drenagem urbana no Brasil, com a ocorrência de problemas associados à impermeabilização do solo em meio urbano, o presente trabalho avaliou a eficiência hidrológica obtida por meio da implantação de telhados verdes e pavimentos permeáveis num condomínio no município de Franca-SP. Tal eficiência foi obtida pela comparação entre volumes escoados superficialmente, considerando a configuração atual do loteamento e de três configurações hipotéticas pela utilização das técnicas compensatórias isoladas ou associadas. As simulações foram realizadas utilizando o Método Santa Bárbara, considerando também as variações de umidade do solo e diferentes cenários de precipitações. Os resultados de eficiência hidrológica foram positivos, sendo que na configuração em que se combinam os telhados verdes aos pavimentos permeáveis obtiveram-se eficiências da ordem de 12,61\% a 73,01\%, em que o primeiro valor ocorre em condições de solo saturado e o segundo em solo seco. Deste modo, ressalta-se a aplicabilidade desses mecanismos, com reduções expressivas de vazões que podem contribuir para o alívio dos sistemas de drenagem urbana e para a redução dos índices de ocorrência de enchentes em meio urbano.

Palavras-chave: Drenagem urbana. Método Santa Bárbara. Telhados verdes. Pavimentos permeáveis.

\section{Abstract}

Given the current scenario of urban drainage in Brazil, with the occurrence of problems associated by soil sealing in urban areas, this paper assessed the hydrological efficiency by the implantation of green roofs and permeable pavements in a residential neighborhood located in the city of Franca-SP. This efficiency was obtained by comparison between runoff volume, considering the current configuration of the subdivision and three hypothetical configurations through the use of isolated or associated best management practices. The simulations were performed using the Santa Barbara method, also considering the variations of soil moisture and different rainfall scenarios. Results of hydrological efficiency are positive, and in the configuration in which the green roofs and the permeable pavements are put together, efficiencies were obtained in order of $12,61 \%$ to $73,01 \%$, where the first value occurs in conditions of saturated soil and the second in dry soil. Thus, it is highlighted the applicability of these mechanisms, with significant reductions in flow rates that may contribute to avoid overloading the urban drainage systems and reduction of urban flash floods.

Keywords: Urban drainage. Santa Barbara method. Green roofs. Permeable pavements.

\footnotetext{
${ }^{1}$ Universidade Federal de Viçosa, Campus de Rio Paranaíba - Minas Gerais - Brasil.

* Autor correspondente: frederico.menezesaufv.br.
} 


\section{INTRODUÇÃO}

A intensa urbanização e consequente impermeabilização do solo impactam o ciclo hidrológico em áreas urbanas, reduzindo a infiltração e aumentando o volume de escoamento superficial.

Segundo Carvalho, Gitirana Jr. e Carvalho (2012), a impermeabilização da superfície natural, unida ao clima tropical brasileiro propenso para ocorrência de chuvas torrenciais, ocasiona os frequentes problemas de enchentes, inundações e assoreamento de cursos d'água e reservatórios, gerando grandes impactos socioambientais e econômicos nas cidades.

Philippi Júnior (2005) atribui como causa do estado caótico dos sistemas de drenagem das grandes cidades brasileiras a falta de planejamento, bem como a ausência de uma visão ambiental urbana integrada e sustentável para o desenvolvimento de projetos na área em questão.

Nesse sentido, as técnicas compensatórias para o manejo de águas pluviais representam alternativas complementares à drenagem convencional, restaurando as condições naturais de pré-urbanização, agindo na redução dos impactos gerados pela impermeabilização (ROY et al., 2008; VASCONCELOS, MIGUEZ e VAZQQUEZ, 2016).

Possuindo outras denominações como Best Management Practices (BMP) ou Melhores Práticas de Manejo (MPM) (MOURA et al., 2014); Low Impact Development (LID), ou ainda, Infraestrutura Verde (CNT, 2010), citam-se como exemplo: os telhados verdes, os pavimentos permeáveis e os sistemas de biorretenção (CRUZ et al., 2007; AGOSTINHO e POLETO, 2012; AHIABLAME et al., 2012).

Os telhados verdes são estruturas destinadas a reduzir o escoamento superficial pela infiltração das águas precipitadas, podendo ser parcialmente ou inteiramente constituídos por vegetação. Representam também uma tecnologia para meIhoria da qualidade das águas pluviais (MORALES et al., 2017), dentre outros benefícios, como a melhoria da qualidade do ar e o conforto térmico com redução do consumo de energia (VIJAYARAGHAVAN et al., 2012), bem como o sequestro de $\mathrm{CO}_{2}$ e a redução de ilhas de calor (CNT, 2010).

Nesta abordagem, Palla et al. (2008) obtiveram por meio do modelo Storm Water Management Model (SWMM) a redução de $51 \%$ da vazão de pico pela aplicação de telhados verdes em $100 \%$ da área de telhados de um bairro, em Gênova Itália, considerando um dispositivo com substrato mais profundo, que permite maiores detenções. As simulações empreendidas por Alamy Filho et al. (2016), utilizando o método Santa Bárbara para um loteamento, apresentaram eficiência máxima de $55,67 \%$ de redução no volume escoado, e uma média de $29,05 \%$ de redução para condições médias de umidade do solo.

Outras técnicas compensatórias de grande utilização são os pavimentos permeáveis. Como abordado por Marchioni e Becciu (2015), em uma extensa revisão bibliográfica, confirma-se a eficiência dos pavimentos permeáveis na redução do volume de escoamento superficial, na remoção de poluentes e a necessidade do encorajamento de seu uso em áreas urbanas.

Esses dispositivos são capazes de reduzir o volume de escoamento superficial e as vazões de pico às condições naturais de infiltração ou até mesmo às taxas de infiltração maiores que as anteriores ao uso do solo, dependendo das condições do subsolo (ARAÚJO, TUCCl e GOLDENFUM, 2000).

Além dos resultados esperados quanto à infiltração e armazenamento das águas pluviais durante as precipitações, segundo o CNT (2010) e Pinto (2011), outras vantagens e benefícios provenientes da utilização do pavimento permeável são a recarga do lençol freático, a melhoria na qualidade das águas, a diminuição dos ruídos e a redução da necessidade de tratamento da água. 


\section{OBJETIVO}

O presente trabalho objetiva avaliar a eficiência hidrológica advinda da implantação de telhados verdes e pavimentos permeáveis num loteamento localizado no município de Franca - SP.

\section{METODOLOGIA}

\section{1 Área de estudo}

Franca é um município do Estado de São Paulo, situado na macrorregião de Ribeirão Preto com aproximadamente 347.640 habitantes (IBGE, 2018). Segundo o Instituto Trata Brasil (2018), ocupa a primeira posição do país no ranking de saneamento básico $O$ único dispositivo legal que trata de maneira indireta a drenagem urbana, es- pecificamente, quanto à redução do escoamento superficial é a Lei que complementa o código de parcelamento de solo do município, a Lei Complementar $N^{\circ} 266$, de 26 de abril de 2016, na seção II. Tal instrumento jurídico estabelece que devem ser mantidos, no mínimo, 30\% da área não edificada de condomínios horizontais constituídos de prédios, com piso drenante ou reserva de área naturalmente permeável (FRANCA, 2016).

No intuito de avaliar a eficiência hidrológica da implantação de telhados verdes, pavimentos permeáveis e da combinação destas estruturas na escala de loteamento, definiu-se como área de estudo o condomínio apresentado na Fig. 1, localizado próximo à região central da cidade de Franca - SP.

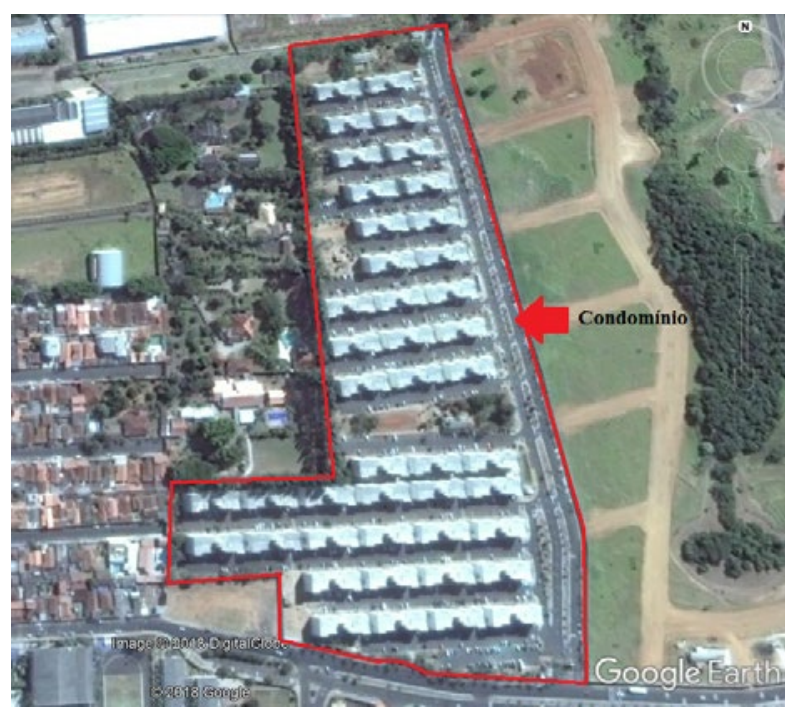

Figura 1 - Condomínio de estudo em destaque (Adaptado de Google Earth).

A área de estudo compreende $100.440 \mathrm{~m}^{2}$, dos quais: $17.116 \mathrm{~m}^{2}$ são de área verde; $18.143 \mathrm{~m}^{2}$ correspondem à área total da cobertura, sendo 44 prédios habitacionais, possuindo cada um cobertura com telhado convencional de $412,33 \mathrm{~m}^{2}$; $41.762 \mathrm{~m}^{2}$ referentes aos pavimentos convencio- nais e $23.419 \mathrm{~m}^{2}$ correspondem às áreas de passeio e construções de uso comum do condomínio, tidos como impermeáveis. Para a obtenção da eficiência hidrológica, as simulações empreendidas contemplaram a implantação das técnicas compensatórias, tão quanto a variação das 
precipitações e condições de umidade do solo, por meio de quatro configurações, a saber:

- Configuração 1: configuração atual presente no condomínio com áreas permeáveis e impermeáveis mantidas;

- Configuração 2: configuração hipotética representada pela substituição dos telhados convencionais por telhados verdes. Aqui, ressalta-se também a avaliação dos efeitos da legislação municipal sobre a área permeável do terreno, que exige $30 \%$, e a soma dos telhados verdes às áreas verdes existentes representando um total de $42 \%$ de áreas permeáveis da área não edificada;

- Configuração 3: configuração hipotética representada pela substituição dos pavimentos convencionais por pavimentos permeáveis;

- Configuração 4: configuração hipotética representada pela combinação de telhados verdes e pavimentos permeáveis substituindo na totalidade as áreas possíveis de telhados e pavimentos convencionais.

\subsection{Equação i-d-f}

Os eventos chuvosos foram calculados com base na equação i-d-f, apresentada pela Eq. 1, adotando-se os parâmetros obtidos para a cidade de Franca, por meio do software Plúvio 2.1 (www. ufv.br/dea/gprh/pluvio), elaborado pelo Grupo de Pesquisa em Recursos Hídricos da Universidade Federal de Viçosa.

$i=\frac{1177,17 \cdot T_{r}^{0,156}}{\left(t_{d}+7,446\right)^{0,794}}$ em que: i: intensidade pluviométrica ( $\mathrm{mm} / \mathrm{hora}$ ); Tr: tempo de retorno (anos) e td: duração do evento (minutos).

\subsection{Simulações Hidrológicas}

Para as simulações executadas neste trabalho foram consideradas diferentes precipitações pela assunção de distintos períodos de retorno (Tr), a saber 2, 5 e 10 anos e distintas durações (td): duração igual ao tempo de concentração do loteamento, 15, 30, 60, 720 e 1440 minutos. A definição do limite superior para (Tr), 10 anos, contemplou o valor máximo adotado para projetos de microdrenagem. Para o limite inferior, buscou-se representar os eventos mais frequentes de chuva. Quanto às durações dos eventos chuvosos, buscou-se representar chuvas curtas e de duração de até um dia, abarcando chuvas de maior e menor intensidade.

A distribuição temporal da chuva seguiu as curvas sintéticas de Huff (1967), demonstradas na Fig. 2, obtidas das curvas apresentadas por Methods e Durrans (2003). Conforme recomenda o autor, para eventos com durações inferiores a 6 horas, considerou-se a curva do $1^{\circ}$ quartil, onde a chuva é mais intensa nos $25 \%$ do intervalo total de sua duração. A curva do $2^{\circ}$ quartil, correspondendo ao pico na parcela de $25 \%$ a $50 \%$ da duração total, foi utilizada para chuvas com durações maiores de 6 a 12 horas. 0 terceiro quartil, que considera as maiores intensidades da precipitação entre $50 \%$ e $75 \%$ do tempo de duração total, foi aplicado para chuvas com durações entre 12 a 24 horas. Neste trabalho não se utilizou a curva do $4^{\circ}$ quartil, devido à não consideração de evento pluviométrico com duração superior a 24 horas. 


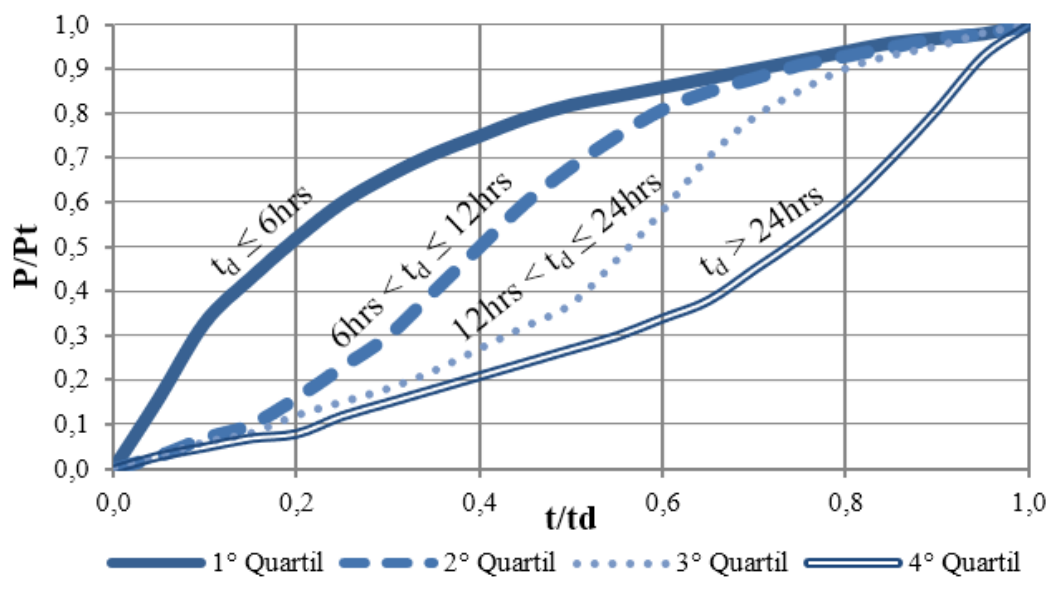

Figura 2 - Gráfico das Curvas de Huff. Fonte: Adaptado de Methods e Durrans (2003).

\subsection{Tempo de concentração}

Para calcular o tempo de concentração para o condomínio em pauta, a fim de estabelecer a duração inicial para os eventos de chuvas simuladas, adotou-se o menor valor para os resultados obtidos pelos métodos de Germano, na Eq. 2, e de Schaake na Eq. 3, conforme descrito por Alamy Filho et al. (2016). A consideração do menor valor representa uma chuva mais intensa, sendo crítica aos sistemas de drenagem. Ambos os métodos de determinação do tempo de concentração utilizados consideram a declividade, o comprimento axial e a parcela de área impermeável contribuinte.

$$
t_{c}=18,628 \frac{L^{0,882}}{\alpha^{0,272}}
$$

em que: $t_{c}$ : tempo de concentração (min); $L$ : comprimento axial da área de estudo $(\mathrm{km})$; $\alpha$ : parcela impermeável da área total.

$t_{c}=0,67 \frac{L^{0,24}}{\alpha^{0,26} \cdot S^{0,16}}$

em que: $t_{c}$ : tempo de concentração (min); L: comprimento axial da área de estudo (m); $\alpha$ : parcela impermeável da área total; $\mathrm{S}$ : declividade média.

\subsection{Determinação da curva número resultante}

A curva número $(\mathrm{CN})$ é um parâmetro adimensional utilizado pelo método do Soil Conservation Service (SCS), atual Natural Resources Conservation Service (NRCS), que está relacionado com a capacidade de infiltração do solo. $\mathrm{O}$ valor de $\mathrm{CN}$ depende do tipo de solo e de sua cobertura, sendo obtido por meio de tabelas apresentadas na literatura como, por exemplo, em Tucci (2004).

Conforme o estudo de Lima (2009), o solo do município de Franca é classificado predominantemente como Latossolo Vermelho-Amarelo e Distrófico, arenoso. Segundo Sartori, Neto e Genovez (2005), tal tipo de solo enquadra-se no grupo hidrológico B, definido por Tucci (2004) como solo menos permeável e arenoso que o do grupo $A$, mas ainda com permeabilidade acima da média.

Deste modo, a definição da curva número para o loteamento baseou-se nos usos do solo existentes na área de estudo, considerando o grupo hidrológico de solo tipo $B$, e três condições de umidade, a saber:

- Condição I (cond. I): condição de solo seco,

- Condição II (cond. II): condições médias de umidade e,

- Condição III (cond. III): condições de solo saturado. 
Para as áreas verdes e telhados verdes, adotouse o valor de $\mathrm{CN}$ equivalente ao de bosques ou zona com cobertura ruim. $\mathrm{O} \mathrm{CN}$ dos pavimentos permeáveis foi adotado como o de vias com paralelepípedos, visto que são pavimentos que apresentam reduções no escoamento devido à infiltração por meio dos blocos. As demais áreas do loteamento correspondem a camadas asfálticas de ruas e estacionamentos, passeios e coberturas das áreas de lazer. Tais valores de $\mathrm{CN}$ em função dos usos dos solos e grupos hidrológicos de solos ( $A, B, C$ e D) são tabelados e podem ser obtidos na literatura.

O valor de $\mathrm{CN}$ resultante foi calculado conforme a Eq. 4, pela média ponderada pelos usos do solo existentes e áreas respectivas.

$\mathrm{CN}=\frac{\mathrm{CN}_{V} \cdot \mathrm{AV}+\mathrm{CN}_{\mathrm{P}} \cdot \mathrm{AP}+\mathrm{CN}_{\mathrm{I}} \cdot \mathrm{Al}}{\mathrm{AT}}$

em que: AV: área verde total, AP: área de pavimentos permeáveis, Al: área impermeável, AT: área total do condomínio, $\mathrm{CN}_{\mathrm{v}}$ : $\mathrm{CN}$ para áreas verdes; $\mathrm{CN}_{\mathrm{p}}$ : $\mathrm{CN}$ para pavimento permeável; $\mathrm{CN}_{1}$ : CN para área impermeável.

\subsection{Método Santa Bárbara}

O modelo hidrológico utilizado neste trabalho foi - Santa Barbara Urban Hidrograph Method (SBUH), desenvolvido por James M. Stubchaer em 1975 no Distrito de Santa Bárbara na Califórnia (STUBCHAER, 1980).

Segundo Tomaz (2012), o método consiste em obter uma relação gráfica de vazão (escoamento) e precipitação para uma determinada bacia de área menor ou igual a $50 \mathrm{~km}^{2}$, considerando as vazões de pico e os intervalos de tempo durante o evento.

A conversão da chuva em escoamento superficial depende diretamente da magnitude das áreas impermeáveis, da permeabilidade do solo, da umidade antecedente e do uso e ocupação da região (ALAMY FILHO et al., 2016).

Tsihrintzis e Sidan (1998) apontam a concordância e a precisão do método principalmente para bacias menores, onde os resultados de escoamento e os hidrogramas elaborados estão próximos da realidade. Os autores ressaltam a aplicabilidade desse mecanismo por sua simplicidade, podendo ser empregado com baixo custo e gerar rápidos resultados.

O mesmo é iniciado pela determinação da precipitação na área intramuros em função da duração da chuva; calculando-se a chuva excedente (runoff) pelo método do SCS, combinando as áreas permeáveis e impermeáveis do local. A diferença entre a precipitação e a chuva excedente equivale ao valor de infiltração. Admite-se um reservatório imaginário para onde se direciona a água do escoamento superficial. Neste passo, consideram-se os efeitos de armazenamento e translação na bacia, para posteriormente calcular a vazão à jusante do condomínio.

Os cálculos, portanto, iniciam-se com a utilização da Eq. 5, referente à precipitação total.

$P_{t}(m m)=i . t_{d}$

em que: i: intensidade da chuva $(\mathrm{mm} / \mathrm{h})$ e $t_{\mathrm{d}}$ : tempo de duração da chuva (h).

Em seguida, obtiveram-se os parâmetros relacionados às superfícies do condomínio, como a capacidade máxima suporte do terreno (S), a abstração inicial $\left(i_{a}\right)$, a parcela de área impermeável (d) e o coeficiente de retardo $\left(k_{\mathrm{r}}\right)$, por meio das Eq. 6 a 9.

$\mathrm{S}(\mathrm{mm})=\frac{25400}{\mathrm{CN}}-254$

em que: $\mathrm{CN}$ : obtido pela Eq. 4. 
$\mathrm{i}_{\mathrm{a}}(\mathrm{mm})=0,2 . \mathrm{S}$

$d=\frac{A l}{A T}$

em que: $\mathrm{Al}$ : soma das áreas impermeáveis $\left(\mathrm{m}^{2}\right)$ e AT : medida total de área do local $\left(\mathrm{m}^{2}\right)$.

$k_{r}=\frac{\Delta t}{2 \cdot t_{c}+\Delta t}$

em que:

- " $\Delta \mathrm{t}$ " : é o incremento em horas, utilizado para cada passo iterativo do método, uma vez que se divide a duração da chuva em faixas para aplicação do método, equivalendo ao número de pontos que resultam no gráfico final de vazão;

- $t_{c}$ : é o tempo de concentração.

Calculados os parâmetros anteriores, aplicaram-se para cada faixa correspondente à distribuição temporal da chuva, os cálculos de chuva por faixa $\left(P_{\text {faixa }}\right)$ e chuva acumulada por faixa $\left(P_{a c}\right)$, pelas Eq. 10 e 11.

$P_{\text {faixa }}(m m)=P_{t} \cdot \%_{\text {HUFF }}$

em que: $\mathbf{P}_{\mathbf{t}}$ : precipitação calculada na equação 5 , e $\%_{\text {HuFF: }}$ porcentagem de chuva que ocorre por faixa segundo a distribuição de Huff.

$P_{a c}(m m)=P_{\text {faixa }}+P_{a c(k-1)}$

em que: $\mathbf{P}_{\mathrm{ac}(\mathbf{k}-1)}$ : precipitação acumulada da faixa anterior, e k: contador de cada processo iterativo.

O escoamento superficial acumulado (Qac) foi obtido pelo método do SCS, pela Eq. 12.

$Q_{a c}(m m)=\frac{\left(P_{t}-i_{a}\right)^{2}}{P_{t}-0,8 . S}$
Posteriormente, calculou-se o runoff que é acrescido por faixa $\left(\mathbf{Q}_{\text {faixa }}\right)$, obtido pela subtração de $\left(\mathbf{Q}_{\mathrm{ac}}\right)$ da faixa atual por $\left(\mathbf{Q}_{\mathrm{ac}}\right)$ da faixa anterior. $E$, logo após, aplicou-se a Eq. 13 para obter a quantidade de infiltração por faixa $\left(\operatorname{lnf}_{\text {faixa }}\right)$ em milímetros.

$\operatorname{Inf}_{\text {faixa }}(\mathrm{mm})=\mathrm{P}_{\text {faixa }}-\mathrm{Q}_{\text {faixa }}$

As Eq. 14 e 15 foram utilizadas para calcular para cada faixa a intensidade do escoamento nas áreas impermeáveis $\left(\mathbf{i}_{\text {imp }}\right)$ e nas áreas permeáveis $\left(\mathbf{i}_{\text {perm }}\right)$.

$\mathrm{i}_{\mathrm{imp}}(\mathrm{mm} / \mathrm{h})=\frac{\mathrm{P}_{\text {faixa }}}{\Delta \mathrm{t}}$

$\mathrm{i}_{\text {perm }}(\mathrm{mm} / \mathrm{h})=\frac{\mathrm{Q}_{\text {faixa }}}{\Delta \mathrm{t}}$

Por meio da Eq. 16 calculou-se a vazão que aflui ao reservatório imaginário por faixa.

$I\left(m^{3} / s\right)=\left[i_{i m p} \cdot d-i_{\text {perm }} \cdot(1-d)\right] \cdot A$

em que: $A$ : área total $(m)$.

A Eq. 17 fornece as vazões de saída do reservatório imaginário para o hidrograma final.

$Q\left(m^{3} /(s)\right)_{k+1}=Q_{k}+k_{r} \cdot\left(I_{k}+I_{k+1}-2 \cdot Q_{k}\right)$

Para as simulações empreendidas neste trabaIho, visto a necessidade de cálculos repetitivos, dispôs-se da rotina em Visual Basic for Aplications (VBA) desenvolvida por Sousa (2008). O código segue o roteiro de cálculo do método Santa Bárbara supracitado e encerra calculando a vazão de pico de saída e o volume total de água escoada para jusante da área de estudo por meio de integração numérica. Neste trabalho, tal rotina foi alterada pelo desconhecimento da fonte refe- 
rente às curvas de Huff utilizadas e pela inserção da idf do município de Franca.

Deste modo, com base nas curvas de Huff apresentadas por Methods e Durrans (2003) (Fig. 2), obtiveram-se as equações polinomiais por meio do ajuste de linhas de tendência, apresentadas na Tabela 1, que foram inseridas na rotina, substituindo as equações iniciais.

Tabela 1 - Equações para cada curva de Huff.

\begin{tabular}{|c|c|c|}
\hline Equação & Quartil & td \\
\hline $\mathrm{P} / \mathrm{Pt}=1,9088 \cdot \mathrm{t} / \mathrm{t}_{\mathrm{d}}{ }^{3}-4,0968 \cdot \mathrm{t} / \mathrm{t}_{\mathrm{d}}{ }^{2}+3,1842 \cdot \mathrm{t} / \mathrm{t}_{\mathrm{d}}+0,0218$ & $1^{\circ}$ & $\mathrm{td}<6 \mathrm{~h}$ \\
\hline$P / P t=4,2875 \cdot t / t_{d}{ }^{4}-10,599 \cdot t / t_{d}{ }^{3}+7,7619 \cdot t / t_{d}{ }^{2}-0,4765 \cdot t / t_{d}+0,0225$ & $2^{\circ}$ & $6 \mathrm{~h}<\mathrm{td} \leq 12 \mathrm{~h}$ \\
\hline $\begin{array}{c}\mathrm{P} / \mathrm{Pt}=42,434 \cdot \mathrm{t}_{\mathrm{t}_{\mathrm{d}}}{ }^{6}-118,88 \cdot \mathrm{t} / \mathrm{t}_{\mathrm{d}}{ }^{5}+117,92 \cdot \mathrm{t} / \mathrm{t}_{\mathrm{d}}{ }^{4}-49,505 \cdot \mathrm{t} / \mathrm{t}_{\mathrm{d}}{ }^{3} \\
+9,0268 \cdot \mathrm{t} / \mathrm{t}_{\mathrm{d}}{ }^{2}-0,0039 \cdot \mathrm{t} / \mathrm{t}_{\mathrm{d}}+0,0041\end{array}$ & $3^{\circ}$ & $12 \mathrm{~h}<\mathrm{td} \leq 24 \mathrm{~h}$ \\
\hline $\begin{array}{c}\mathrm{P} / \mathrm{Pt}=-20,591 \cdot \mathrm{t} / \mathrm{t}_{\mathrm{d}}{ }^{6}+55,342 \cdot \mathrm{t} / \mathrm{t}_{\mathrm{d}}{ }^{5}-53,606 \cdot \mathrm{t} / \mathrm{t}_{\mathrm{d}}{ }^{4}+23,45 \cdot \mathrm{t} / \mathrm{t}_{\mathrm{d}}{ }^{3} \\
-4,3118 \cdot \mathrm{t} / \mathrm{t}_{\mathrm{d}}{ }^{2}-0,7184 \cdot \mathrm{t} / \mathrm{t}_{\mathrm{d}}+0,001\end{array}$ & $4^{\circ}$ & $t d>24 h$ \\
\hline
\end{tabular}

Fonte: Autores.

\subsection{Eficiência hidrológica}

No intuito de quantificar a eficiência hidrológica entre os volumes gerados pela configuração 1, representando o cenário atual e as demais configurações caracterizadas pelo uso de telhados verdes e pavimentos permeáveis, tanto quanto a combinação destes, utilizou-se a Eq. 18, apresentada por Alamy Filho et al. (2016):

$E(\%)=\frac{100 \cdot\left(V_{i}-V_{s}\right)}{V_{i}}$

em que: $E(\%)$ : eficiência hidrológica, $V_{i}$ é o volume total escoado na configuração atual do condomínio e $V_{s}$ é o volume total escoado para cada uma das outras três configurações.

\section{RESULTADOS}

Foram empreendidas 216 simulações para estabelecer as variações das vazões de pico e vo- lumes escoados para cada configuração física e cenários de precipitação propostos.

Os resultados das simulações e eficiências calculadas estão reunidos nos Apêndices A e B, respectivamente. Os valores de tempo de concentração e CN para cada configuração e condição de umidade estão dispostos na Tabela 2.

As condições de umidade admitidas permitem obter dados que representam resultados aplicáveis ao longo de um ano hidrológico, com suas variações de umidade em cada período do ano. Ressalta-se a elevada variação dos valores de curva número resultante para as configurações que possuem pavimentos permeáveis (configurações 3 e 4), fato que ocorre devida às variações para cada condição da tabela apresentada por McCuen (1998), combinadas ao alto percentual de área que se substitui o pavimento convencional. 
Tabela 2 - Valores de CN resultantes.

\begin{tabular}{|c|c|c|c|c|c|c|c|c|}
\hline \multicolumn{9}{|c|}{ PARÂMETROS PARA CADA CONFIGURAÇÃO } \\
\hline \multirow[b]{2}{*}{ Config. } & \multirow[b]{2}{*}{ Tc (min) } & \multicolumn{4}{|c|}{ Áreas Resultantes $\left(\mathbf{m}^{2}\right)$} & \multicolumn{3}{|c|}{ CN Resultante } \\
\hline & & Área Verde & $\begin{array}{c}\text { Área } \\
\text { Impermeável }\end{array}$ & $\begin{array}{l}\text { Pavimento } \\
\text { Permeável }\end{array}$ & $\begin{array}{c}\text { Área } \\
\text { permeável } \\
\text { total (\%) }\end{array}$ & Condição I & Condição II & Condição III \\
\hline 1 & 1,43 & 17116,0 & 83324,0 & 0,0 & 17,0 & 85,8 & 92,0 & 96,4 \\
\hline 2 & 1,53 & 35258,7 & 65181,3 & 0,0 & 35,1 & 77,0 & 86,8 & 93,7 \\
\hline 3 & 1,72 & 17116,0 & 41562,0 & 41762,0 & 58,6 & 75,8 & 87,0 & 96,7 \\
\hline 4 & 1,99 & 35258,7 & 23419,3 & 41762,0 & 76,7 & 66,0 & 81,0 & 92,0 \\
\hline
\end{tabular}

Nas Fig. 3, 4 e 5 apresentam-se os mapas de calor gerados resultantes da comparação entre a configuração 1 (cenário atual) com as configurações 2,3 e 4 , respectivamente, cenário com telhados verdes, pa- vimentos permeáveis e, por fim a associação entre as duas estruturas. Nestes mapas, têm-se as eficiências hidrológicas em função do período de retorno, duração das chuvas e condição de umidade do solo.
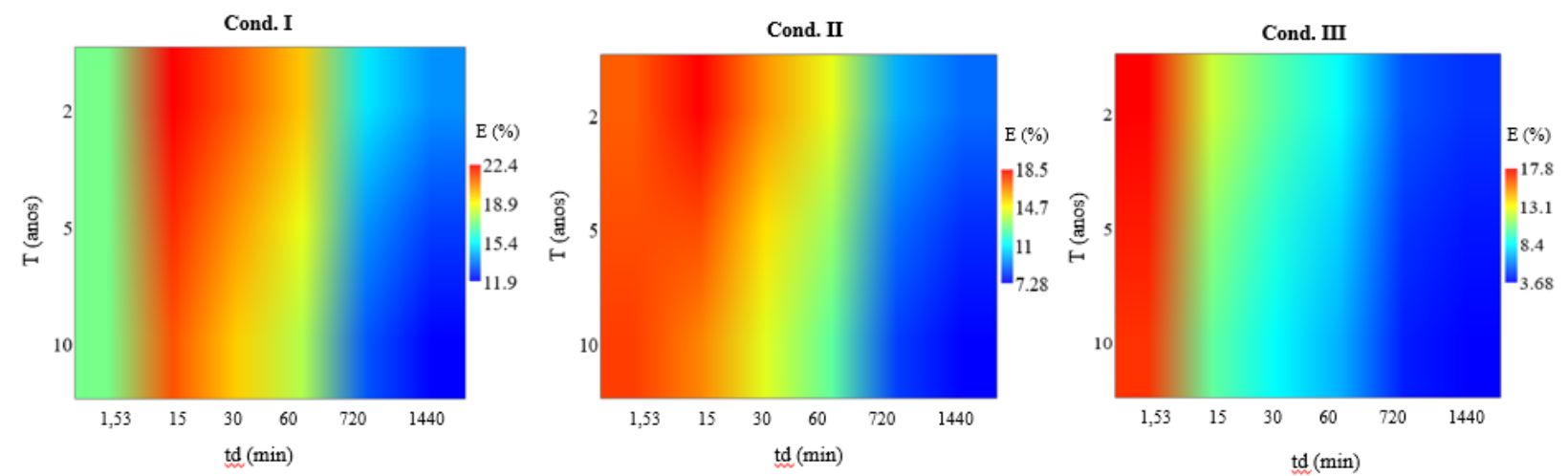

Figura 3 - Mapas de calor para as eficiências da configuração 2 em relação à configuração 1. Legenda: T - período de retorno; td - duração da chuva; Cond. I - condição de umidade referente a solo seco; Cond. II - condição média de umidade e Cond. III - condição de umidade referente a solo saturado. Fonte: Autores.

De modo geral, observa-se que, para as 3 configurações apresentadas (2, 3 e 4), as taxas de infiltração do loteamento, vinculadas às eficiências hidrológicas, são maiores em chuvas com duração de até 60 minutos para as condições I e II de umidade. Para a condição III, as maiores eficiências encontram-se para as durações de até 15 minutos.
Quanto ao período de retorno, as maiores eficiências são verificadas, em geral, para os menores valores. Para chuvas de 12 e 24 horas, as eficiências hidrológicas reduzem de acordo com as condições de umidade e configuração, sendo maiores para o solo seco (cond. I) e Configuração 4, dada pela associação entre telhados verdes e pavimentos permeáveis. 

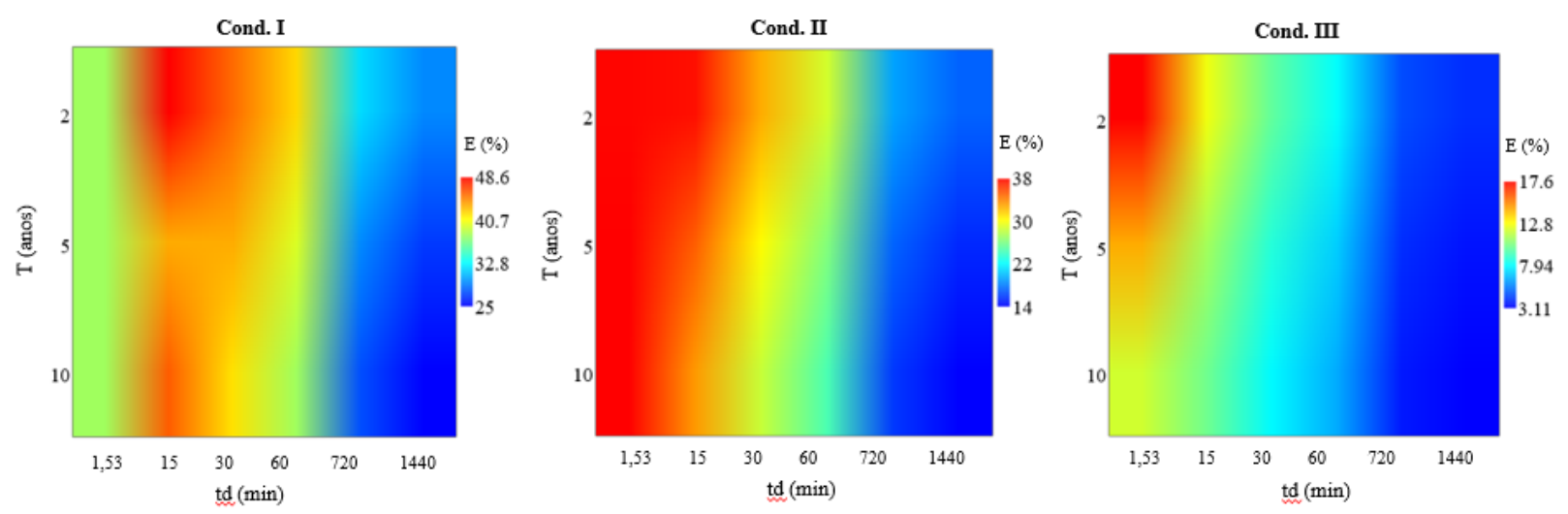

Figura 4 - Mapas de calor para as eficiências da configuração 3 em relação à configuração 1. Legenda: T - período de retorno; td - duração da chuva; Cond. I - condição de umidade referente a solo seco; Cond. II - condição média de umidade e Cond. III - condição de umidade referente a solo saturado. Fonte: Autores.
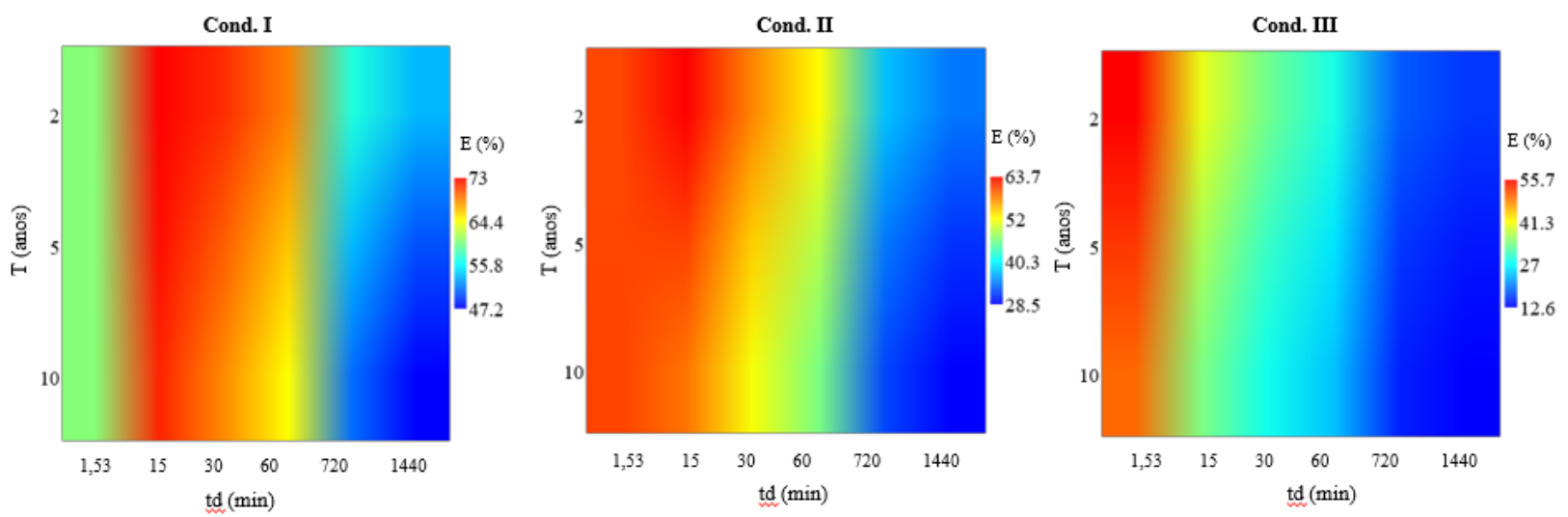

Figura 5 - Mapas de calor para as eficiências da configuração 4 em relação à configuração 1. Legenda: T - período de retorno; td - duração da chuva; Cond. I - condição de umidade referente a solo seco; Cond. II - condição média de umidade e Cond. III - condição de umidade referente a solo saturado.

Fonte: Autores.

A condição Il de umidade média apresenta resultados intermediários às outras condições.

Nos períodos de seca, representados pela condição I de umidade, ocorrem maiores eficiências dos sistemas, devido ao potencial de infiltração elevado do solo, e em contrapartida, em dias chuvosos, em que o solo está na iminência de ser saturado, as eficiências são reduzidas. Tal interpretação é justificável, uma vez que ambos os sistemas propostos possuem limitações de armazenamento e taxa de infiltração.

Outra apresentação dos resultados de eficiências hidrológicas obtidos pode ser feita por meio de grá- fico box-plot ou diagrama de caixa, apresentado na Fig. 6. Nesta, é possível aferir os valores máximos e mínimos encontrados para cada combinação, bem como o $1^{\circ}$ quartil, o $3^{\circ}$ quartil e a mediana.

Por meio da Fig. 6, tem-se que a eficiência máxima da configuração 2 com relação à configuração 1 na condição de solo seco (umidade I), representada pelo telhado verde (TV), é de $22,41 \%$. Tal valor fora obtido para o período de retorno de 2 anos e duração de 15 minutos, o que é representativo de eventos mais frequentes de chuva. Já a menor eficiência para a mesma combinação é de $3,68 \%$, obtida para um período de retorno de 10 anos, e duração de 24 horas em solo 
saturado. Valor este que já representa uma chuva prolongada e menos frequente que a primeira.

Também na Fig. 6, nota-se que a configuração 3, representada pela implantação dos pavimentos permeáveis (PV), apresentou a eficiência máxima de $48,57 \%$ e mínima de 3,11\%, ambas ocorrendo nos mesmos cenários de máxima e mínima da combinação anterior.

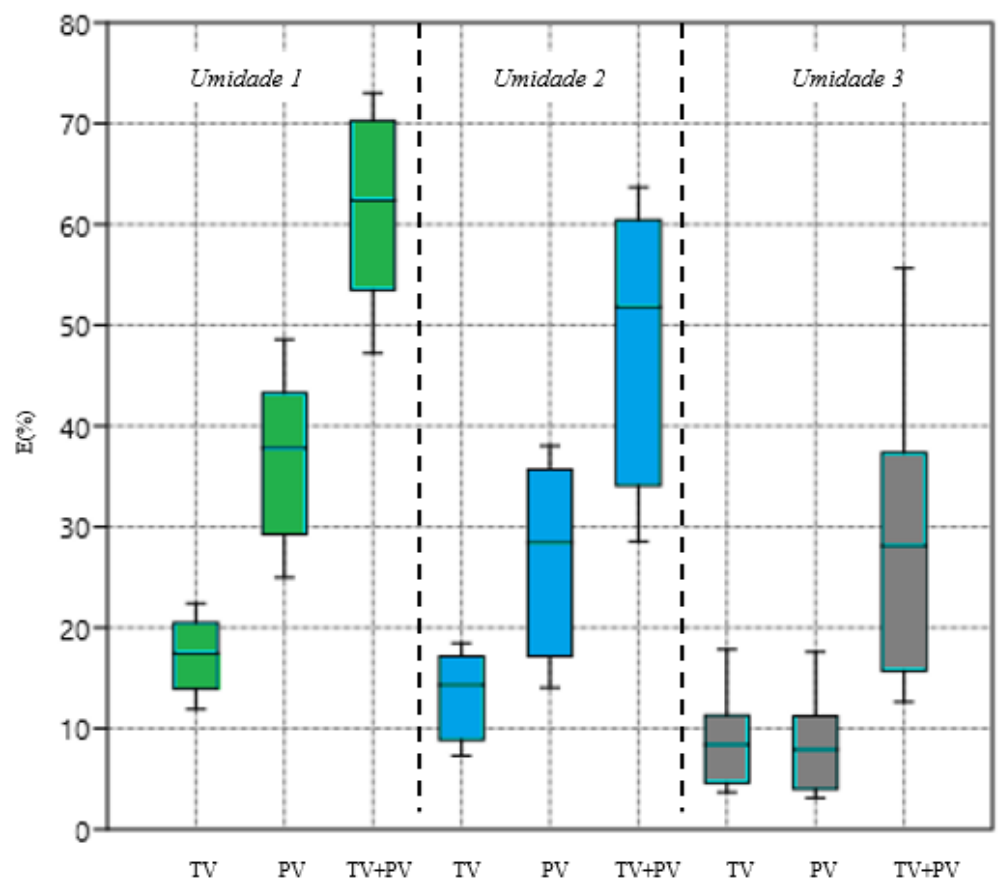

Figura 6 - Diagrama de caixa para a eficiência hidrológica em função da associação das estruturas e de condições antecedentes de umidade do solo.

Legenda: TV-telhado verde; PV-pavimento permeável; TV + PV - associação de telhado verde e pavimento permeável. Fonte: Autores.

A configuração 4, representada pela associação de telhados e pavimentos (TV + PV), resultou na eficiência máxima de $73,01 \%$ para um período de retorno de 2 anos, e duração de 15 minutos em solo seco, e $12,61 \%$ de eficiência mínima, ocorrendo em solo saturado, para um período de retorno de 10 anos e 24 horas de duração. Ressalta-se também que, nesta última combinação, o pior cenário de precipitação, com $\mathrm{T}=10$ anos e td $=24$ horas, em solo seco, ainda apresenta alta eficiência hidrológica, equivalente a 47,23\%.

Os resultados da Fig. 6 demonstram com clareza a influência da umidade do solo na eficiência de cada combinação, bem como salienta quão maiores são as eficiências médias quando se combinam os dispositivos de telhados verdes com os pavimentos permeáveis no mesmo loteamento, (situação TV+PV).

A configuração 3 (PV) sob condições de solo saturado apresenta elevada redução de eficiência com relação às condições médias. $O$ valor máximo cai de $48,57 \%$ (condição I) para 17,59\% (condição III). Essa amplitude é decorrente do valor de $\mathrm{CN}=$ 97 adotado para pavimentos permeáveis em solo saturado, o que, para efeito de cálculo, reduz consideravelmente a taxa de infiltração dos pavimentos.

As relações diretas das precipitações $(\mathrm{Pt})$ com as eficiências de cada uma das configurações hipotéticas permitiram a elaboração de gráficos de dispersão dispostos no Apêndice $C$ e a consequente obtenção de equações por meio do ajuste 
de linhas de tendência. Essa análise é importante para evidenciar a variação da infiltração dos dispositivos com o aumento da altura pluviométrica, como apresentado nas Fig, 3, 4 e 5.

As equações de eficiência versus precipitação em função do uso dos telhados verdes, pavimentos ou associação de ambos, considerando as condições de umidade para o loteamento em questão, são apresentadas na Tabela 3. Tais equações permitem, portanto, o cálculo expedito da eficiência hidrológica em função da lâmina precipitada, tendo como base a condição de umidade do solo e a configuração do sistema.

Tabela 3 - Equações de eficiência (\%) versus precipitação em função do uso de técnicas e condições de umidade antecedente do solo. Aplicáveis na faixa: $(5,52$ " $\leq \mathrm{P}(\mathrm{mm}) \leq 125,18)$ " .

\begin{tabular}{|c|c|c|}
\hline \multicolumn{3}{|c|}{ Condição de umidade 1 (solo seco) } \\
\hline Estruturas & Equação & $\mathbf{R}^{2}$ \\
\hline Telhados Verdes & $E=-6 \cdot 10-7 \cdot P^{4}+0,0002 \cdot P^{3}-0,0204 \cdot P^{2}+0,7389 \cdot P+13,20$ & 0,992 \\
\hline Pavimentos Permeáveis & $E=-1 \cdot 10-6 \cdot P^{4}+0,0003 \cdot P^{3}-0,0374 \cdot P^{2}+1,3415 \cdot P+30,84$ & 0,983 \\
\hline Telhados Verdes e Pav. Permeáveis & $E=7 \cdot 10-5 \cdot P^{3}-0,017 \cdot P^{2}+0,9351 \cdot P+55,73$ & 0,975 \\
\hline \multicolumn{3}{|c|}{ Condição de umidade 2 (condições médias) } \\
\hline Estruturas & Equação & $\mathbf{R}^{\mathbf{2}}$ \\
\hline Telhados Verdes & $E=-5 \cdot 10-7 \cdot P^{4}+0,0001 \cdot P^{3}-0,0142 \cdot P^{2}+0,3708 \cdot P+15,563$ & 0,995 \\
\hline Pavimentos Permeáveis & $E=-9 \cdot 10-7 \cdot P^{4}+0,0003 \cdot P^{3}-0,0242 \cdot P^{2}+0,5022 \cdot P+35,781$ & 0,996 \\
\hline Telhados Verdes e Pav. Permeáveis & $E=-1 \cdot 10-6 \cdot P^{4}+0,0004 \cdot P^{3}-0,0405 \cdot P^{2}+1,0667 \cdot P+55,432$ & 0,996 \\
\hline \multicolumn{3}{|c|}{ Condição de umidade 3 (solo saturado) } \\
\hline Estruturas & Equação & $\mathbf{R}^{2}$ \\
\hline Telhados Verdes & $E=17,037 \cdot e^{-0,013 \cdot P}$ & 0,977 \\
\hline Pavimentos Permeáveis & $E=15,896 . e^{-0,014 . P}$ & 0,972 \\
\hline Telhados Verdes e Pav. Permeáveis & $E=53,549 \cdot e^{-0,012 . P}$ & 0,985 \\
\hline
\end{tabular}

Nas Fig. 7 e 8, apresentam-se os hidrogramas resultantes das maiores e menores eficiências hidrológicas, correspondentes a chuvas de
15 minutos e períodos de retorno de dois anos, e chuva de 24 horas com período de retorno de 10 anos respectivamente.

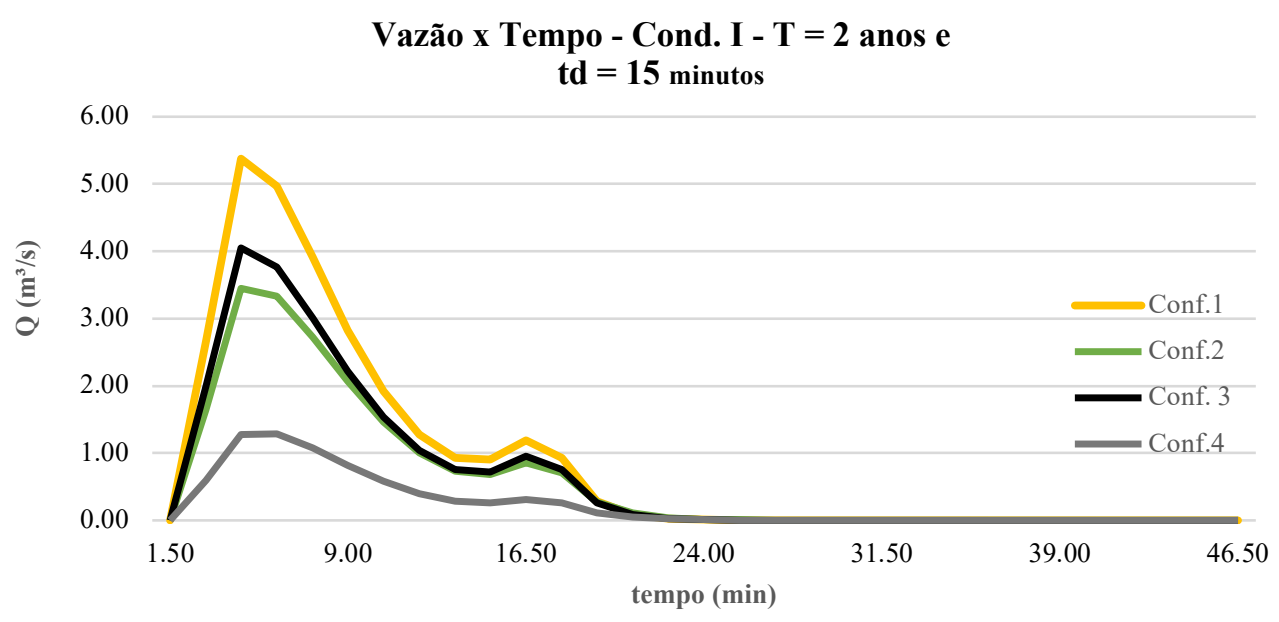

Figura 7 - Gráfico de Q x td para condição I.

Fonte: Autores. 
Para o melhor cenário, como esperado, as vazões de pico decrescem do cenário atual, sem estruturas, para o menor valor representativo do cenário com a associação entre telhados e pavimentos permeáveis.

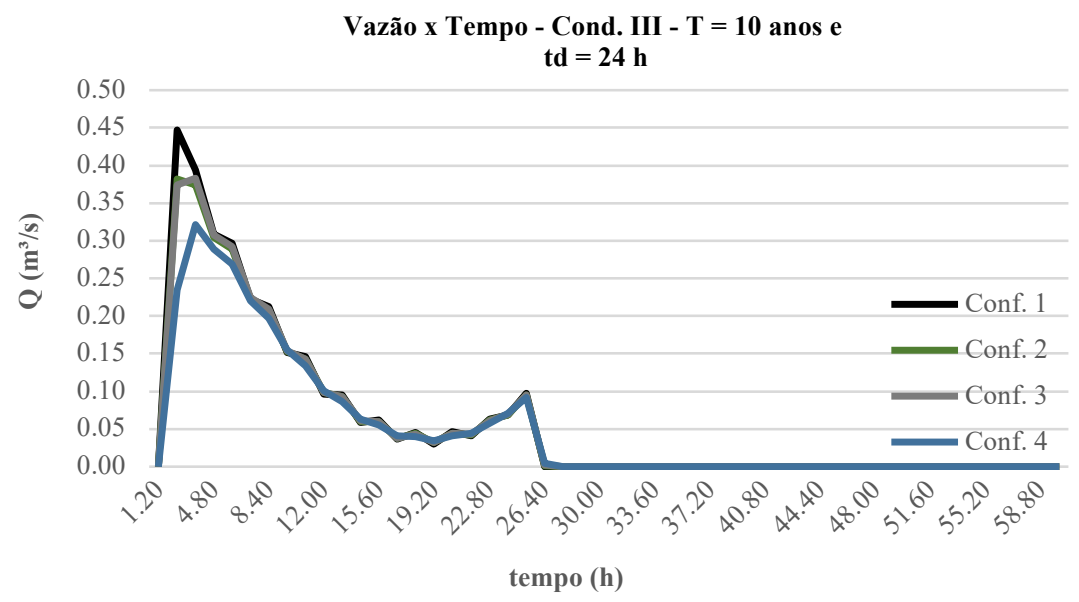

Figura 8 - Gráfico de Q x td para condição III. Fonte: Autores.

Considerando a Fig. 7, para as condições de umidade referente ao solo seco com precipitação de 27,73 mm e intensidade pluviométrica de 110,92 $\mathrm{mm} / \mathrm{h}$, as vazões de pico reduziram de $5,38 \mathrm{~m}^{3} / \mathrm{s}$ (configuração 1), para $4,05 \mathrm{~m}^{3} / \mathrm{s}$ (configuração 2), depois para $3,45 \mathrm{~m}^{3} / \mathrm{s}$ (configuração 3 ) e 1,29 $\mathrm{m}^{3} / \mathrm{s}$ (configuração 4).

No cenário de pior eficiência apresentado pela Fig. 8 com chuva de 125,18 mm, a configuração 1 tem vazão máxima de $0,46 \mathrm{~m}^{3} / \mathrm{s}$, enquanto a menor vazão de pico (configuração 4) é de $0,32 \mathrm{~m}^{3} / \mathrm{s}$. Esse cenário, apesar do baixo valor percentual de eficiência, reflete chuvas de baixa intensidade ( $T=10$ anos, $t d=24$ horas, $i=5,2 \mathrm{~mm} / \mathrm{h}$ ), não incorrendo em problemas para a drenagem do loteamento. Os resultados reafirmam a eficiência dos mecanismos sugeridos, enfatizando o efeito dos telhados verdes somados aos pavimentos permeáveis.

\section{CONCLUSÕES}

Os resultados do presente trabalho corroboram a eficiência hidrológica da utilização de técnicas compensatórias, sejam elas telhados verdes ou pavimentos permeáveis, na redução das vazões de pico e volume de escoamento superficial.

Quanto aos resultados obtidos, a configuração 2, caracterizada pela implantação de telhados verdes no loteamento, apresentou um percentual possível de $42 \%$ de área permeável da área não edificada. Tal valor, superior aos $30 \%$ exigidos pela legislação municipal, refletiu uma faixa de eficiência de 3 a 23\%. Assim, mesmo cumprindo a legislação, o escoamento superficial pouco se alteraria, acenando para uma necessidade de elevar a exigência maior quanto às áreas permeáveis em loteamentos no município de estudo. Já para a configuração 4, resultante do uso de telhados verdes e de pavimentos permeáveis no loteamento, obteve-se a eficiência máxima de 73,01\% com relação às condições atuais, representando a situação ideal. Todavia, as configurações 2 e 3 também possuem aplicabilidade, visto que apresentam eficiências que, ainda que menores (de $3,11 \%$ a $48,57 \%$ para configuração 3), indicam possível melhoria nas condições de impermeabilização atuais. 
Deste modo, ressalta-se que a associação entre as técnicas compensatórias e os sistemas clássicos de drenagem possibilitam, além dos benefícios ambientais citados neste artigo, a redução dos custos totais relativos à implantação de galerias de águas pluviais, pela consequente redução de diâmetros, vista a redução do escoamento superficial. Em paralelo, a valoração ambiental que se apresenta na utilização de tais estruturas em meio urbano é inquestionável, seja pela infiltração das águas pluviais, pela redução das ilhas de calor, pelo sequestro de carbono, por questões paisagísticas, dentre outros.

\section{CONTRIBUIÇÃO DOS AUTORES}

Todos os autores contribuíram de forma igualitária.

\section{REFERÊNCIAS}

AGOSTINHO, M. S. P.; POLETO, C. Sistemas Sustentáveis de Drenagem Urbana: Dispositivos. HOLUS Environment. Vol 12, n. 2, p. 121, 2012. Disponível em: < https://www.cea-unesp.org.br/ holos/article/view/3054> Acesso em: 26 fev. 2018. https://doi. org/10.14295/holos.v12i2.3054

AHIABLAME, L. M.; ENGEL, B. A.; CHAUBEY, I. Effectiveness of Low Impact Development Practices: Literature Review and Suggestions for Future Research. Water Air Soil Pollut. vol. 223 p.42534273, jun. 2012. https://doi.org/10.1007/s11270-012-1189-2

ALAMY FILHO, J. E.; et al. Eficiência hidrológica de telhados verdes para a escala de loteamentos residenciais. Soc. \& Nat. Uberlândia. Vol. 28, n. 2, p. 257-272. mai/ago. 2016. https://doi. org/10.1590/1982-451320160206

ARAÚJO, P. R.; TUCCI, C. E. M.; GOLDENFUM, J. A., Avaliação da eficiência dos pavimentos permeáveis na redução do escoamento superficial. Revista Brasileira de Recursos Hídricos. Vol. 5, n. 3, p. 21-29. Jul/Set. 2000.

CARVALHO, J. C.; GITIRANA. JR, G. F. N.; CARVALHO, E. T. L. Tópicos sobre infiltração: Teoria e prática aplicadas a solos tropicais. Faculdade de Tecnologia, Série Geotecnia - UnB. Brasília, 2012. Vol. 4, 644p.

CNT. The Value of Green Infrastructure: A Guide to Recognizing Its Economic, Environmental and Social Benefits. Chicago. 2010.

CRUZ, M. A. S.; SOUZA, C. F.: TUCCI, C. E. M. Controle de Drenagem Urbana no Brasil: Avanços e Mecanismos para sua Sustentabili- dade. Simpósio Brasileiro de Recursos Hídricos, XVII, 2007, São Paulo. Anais... Disponível em: http://rhama.com.br/blog/wp-content/uploads/2017/04/controledrenagemurbana.pdf>. Acesso em: 26 fev. 2018.

FRANCA. Lei Orgânica do Município De Franca, de 05 de abril de 1990. Dispõe sobre a Lei Orgânica de Franca. Franca SP, abril de 1990.

FRANCA. Lei Complementar No 9, de 26 de novembro de 1996. Institui o Código do Meio Ambiente do Município de Franca, SP. Franca SP, novembro de 1996.

FRANCA. Lei Complementar $\mathbf{N}^{\circ}$ 266, de 26 de abril 2016. Altera a Lei Complementar $n^{\circ} 137$, de 18 de dezembro de 2008, que dispõe sobre o Parcelamento do Solo no Município de Franca e dá outras providências. Franca SP, abril de 2016.

HUFF, F. A. Time distribution of rainfall in heavy storms. Water Resouces Research. vol. 3. n. 4. p.1007-1019. 1967. https://doi. org/10.1029/WR003i004p01007

INSTITUTO BRASILEIRO DE GEOGRAFIA ESTATÍSTICA. Franca. Disponível em: <https://www.ibge.gov.br/estatisticas-novoportal/por-cidade-estado-estatisticas.html?t=destaques $\& c=3516200>$. Acesso em: 04 jul. 2018

INSTITUTO TRATA BRASIL, Ranking do Saneamento. São Paulo, abr. 2018. Disponível em: <http://www.tratabrasil.org.br/images/ estudos/itb/ranking-2018/realatorio-completo.pdf> Acesso em: 04 jul. 2018.

LIMA, M. M. Zoneamento ambiental do município e região de Franca - SP, (Trabalho de conclusão de curso, graduação), UNESP, Rio Claro, SP. out. de 2009.

MARCHIONI, M.; BECCIU, G. Experimental results on permeable pavements in urban áreas: a synthetic review. International Journal of Sustainable Development and Planning. Vol. 10, No. 7. 806-817. 2015. https://doi.org/10.2495/SDP-V10-N6-806-817

MARTINS, J. R. S. Gestão da drenagem urbana: só tecnologia será suficiente?. Escola Politécnica, Universidade de São Paulo. São Paulo, 2012. Disponível em: <http://www.daee.sp.gov.br/ outorgatreinamento/Obras_Hidr\%C3\%A1ulic/gestaodrenagem. pdf>. Acesso em: 26 fev. 2018.

METHODS, H; DURRANS, S. R. Stormwater conveyance modeling and design. First Edition. Waterbury, USA: Haestad Press, 2003.

McCuen, R.H., Hydrologic analysis and design. 2. ed. Upper Saddle River, NJ. Prentice Hall, 814 p., 1998.

MORALES, J. A; CRISTANCHO, M. A; BAQUERO-RODRIGUES, G. A. Trends in the design, constrution and operation of green roofs to improve the Rainwater quality, State of the art. Ingenieria del agua, 21 (3), 179-186. https://doi.org/10.4995/la.2017.6939

MOURA, N. C. B; PELLEGRINO, P. R. M.; MARTINS, J. R. S. Transição em infraestruturas urbanas e de controle pluvial: uma estratégia paisagística de adaptação às mudanças climáticas. 
Paisagem e ambiente, n.34. São Paulo. p.107-128. 2014. https:// doi.org/10.11606/issn.2359-5361.v0i34p107-128

PALLA, A. et al. Modelling storm water control operated by green roofs at the urban catchment scale. In: International Conference on Urban Drainage, 21, Ed-inburgh, Scotland, UK, pp. 1-10, 2008. Anais... Disponível em: < http://web.sbe.hw.ac.uk/staffprofiles/ bdgsa/11th_International_Conference_on_Urban_Drainage_CD/ ICUD08/pdfs/245.pdf>. Acesso em: jun. 2018.

PHILIPPI. JR, A. Saneamento, Saúde e Ambiente: Fundamentos para um desenvolvimento sustentável. 1. ed. Barueri, SP. Manole, 2005.

PINTO, L. L. C. A. O Desempenho de Pavimentos Permeáveis Como Medida Mitigadora da Impermeabilização do Solo Urbano. Tese (Doutorado). Escola Politécnica, Universidade de São Paulo, São Paulo, 2011. 255 p.

ROY, A. H. et al. R. Impediments and solutions to sustainable, atershed-scale urbanstormwater management: lessons from Australia and the United States. Environmental Management, vol. 42, n. 2, p. 344-359. 2008.

SARTORI, A.; LOMBARDI NETO, F.; GENOVEZ, A. M. Classificação Hidrológica de Solos Brasileiros para a Estimativa de Chuva Excedente com o Método do Serviço de Conservação de Solo dos Estados Unidos Parte 1: Classificação, Revista Brasileira de Recursos Hídricos, vol. 10, n. 4, p. 5-18, out/dez. 2005. https://doi. org/10.21168/rbrh.v10n4.p5-18
SOUSA, J. S. Áreas de preservação permanente urbanas, mapeamento, diagnósticos, índices de qualidade ambiental e influência no escoamento superficial, Dissertação (Mestrado), FECIV/ UFU, Uberlandia, MG, jul de 2008.

STUBCHAER, J.M. The Santa Barbara urban hy-drograph method. Proceedings of the National Sym $p$ posium of Hydrology and Sediment Control. Lexington, New York, USA, 1980.

TUCCI, C. E. M. Hidrologia ciência e aplicação. 3 ed. Porto Alegre, RS: Editora da UFRGS/ABRH, 2004. 943p.

TOMAZ, P. Curso de Manejo de Águas Pluviais. Guarulhos. nov. de 2012. Cap. 24.

TSIHRINTZIS, V. A. e SIDAN, C. B., Modeling Urban Stormwater Runoff Processes Using the Santa Barbara Method. Water Resources Management. Vol. 12, p. 139-166, 1998.

VASCONCELOS, A. F.; MIGUEZ, M. G.; VAZQUUEZ, E. G. Critérios de projeto e benefícios esperados da implantação de técnicas compensatórias em drenagem urbana para controle de escoamentos na fonte, com base em modelagem computacional aplicada a um estudo de caso na zona oeste do Rio de Janeiro. Engenharia Sanitária e Ambiental. vol.21, n.4, p. 655-662, Out. 2016. https://doi. org/10.1590/s1413-41522016146469

VIJAYARAGHAVAN, K.; JOSHI, U. M.; BALASUBRAMANIAN, R. A field study to evaluate runoff quality from green roofs. Water Research. v. 46, n. 4, p. 1337-1345, 2012. https://doi.org/10.1016/j. watres.2011.12.050

\section{APÊNDICE A - Tabelas de resultados de vazão e volume escoado para cada simulação}

Tabela A1 - Resultados da configuração 1 para condição de umidade I.

\begin{tabular}{|c|c|c|c|c|c|c|c|c|c|c|c|c|c|}
\hline \multicolumn{14}{|c|}{ Configuração 1} \\
\hline & & \multicolumn{12}{|c|}{ Tempo de Duração } \\
\hline & & \multicolumn{2}{|c|}{ tc $=1,43 \mathrm{~min}}$. & \multicolumn{2}{|c|}{$15 \mathrm{~min}}$. & \multicolumn{2}{|c|}{$30 \mathrm{~min}}$. & \multicolumn{2}{|c|}{$60 \mathrm{~min}}$. & \multicolumn{2}{|c|}{12 horas } & \multicolumn{2}{|c|}{24 horas } \\
\hline & & $\begin{array}{c}\text { Vazão } \\
\text { de Pico } \\
\left(\mathrm{m}^{3} / \mathrm{s}\right)\end{array}$ & $\begin{array}{c}\text { Vol. } \\
\text { Escoado } \\
\left(\mathrm{m}^{3}\right)\end{array}$ & $\begin{array}{l}\text { Vazão } \\
\text { de Pico } \\
\left(\mathrm{m}^{3} / \mathrm{s}\right)\end{array}$ & $\begin{array}{c}\text { Vol. } \\
\text { Escoado } \\
\left(\mathrm{m}^{3}\right)\end{array}$ & $\begin{array}{c}\text { Vazão } \\
\text { de Pico } \\
\left(\mathrm{m}^{3} / \mathrm{s}\right)\end{array}$ & $\begin{array}{c}\text { Vol. } \\
\text { Escoado } \\
\left(\mathrm{m}^{3}\right)\end{array}$ & $\begin{array}{c}\text { Vazão } \\
\text { de Pico } \\
\left(\mathrm{m}^{3} / \mathrm{s}\right)\end{array}$ & $\begin{array}{c}\text { Vol. } \\
\text { Escoado } \\
\left(\mathrm{m}^{3}\right)\end{array}$ & $\begin{array}{c}\text { Vazão } \\
\text { de Pico } \\
\left(\mathrm{m}^{3} / \mathrm{s}\right)\end{array}$ & $\begin{array}{c}\text { Vol. } \\
\text { Escoado } \\
\left(\mathrm{m}^{3}\right)\end{array}$ & $\begin{array}{c}\text { Vazão } \\
\text { de Pico } \\
\left(\mathrm{m}^{3} / \mathrm{s}\right)\end{array}$ & $\begin{array}{c}\text { Vol. } \\
\text { Escoado } \\
\left(\mathrm{m}^{3}\right)\end{array}$ \\
\hline \multirow{3}{*}{$\begin{array}{l}\text { Período de } \\
\text { retorno } \\
\text { (anos) }\end{array}$} & 2 & 3.24 & 409.9 & 5.38 & 2458.2 & 4.50 & 3336.7 & 3.05 & 4264.6 & 0.06 & 7988.1 & 0.03 & 9313.9 \\
\hline & 5 & 3.74 & 472.9 & 6.23 & 2861.3 & 5.23 & 3885.0 & 3.55 & 4964.5 & 0.07 & 9284.6 & 0.04 & 10819.9 \\
\hline & 10 & 4.17 & 526.9 & 6.97 & 3210.1 & 5.86 & 4358.7 & 3.98 & 5568.4 & 0.07 & 10399.9 & 0.04 & 12114.6 \\
\hline
\end{tabular}

Tabela A2 - Resultados da configuração 2 para condição de umidade I.

\begin{tabular}{|c|c|c|c|c|c|c|c|c|c|c|c|c|c|}
\hline \multicolumn{14}{|c|}{ Configuração 2} \\
\hline & & \multicolumn{12}{|c|}{ Tempo de Duração } \\
\hline & & \multicolumn{2}{|c|}{$\mathrm{tc}=1,53$} & \multicolumn{2}{|c|}{$15 \mathrm{~min}}$. & \multicolumn{2}{|c|}{$30 \mathrm{~min}}$. & \multicolumn{2}{|c|}{$60 \mathrm{~min}}$. & \multicolumn{2}{|c|}{12 horas } & \multicolumn{2}{|c|}{24 horas } \\
\hline & & $\begin{array}{c}\text { Vazão } \\
\text { de Pico } \\
\left(\mathrm{m}^{3} / \mathrm{s}\right)\end{array}$ & $\begin{array}{c}\text { Vol. } \\
\text { Escoado } \\
\left(\mathrm{m}^{3}\right)\end{array}$ & $\begin{array}{c}\text { Vazão } \\
\text { de Pico } \\
\left(\mathrm{m}^{3} / \mathrm{s}\right)\end{array}$ & $\begin{array}{c}\text { Vol. } \\
\text { Escoado } \\
\left(\mathrm{m}^{3}\right)\end{array}$ & $\begin{array}{c}\text { Vazão } \\
\text { de Pico } \\
\left(\mathrm{m}^{3} / \mathrm{s}\right)\end{array}$ & $\begin{array}{c}\text { Vol. } \\
\text { Escoado } \\
\left(\mathrm{m}^{3}\right)\end{array}$ & $\begin{array}{c}\text { Vazão } \\
\text { de Pico } \\
\left(\mathrm{m}^{3} / \mathrm{s}\right)\end{array}$ & $\begin{array}{c}\text { Vol. } \\
\text { Escoado } \\
\left(\mathrm{m}^{3}\right)\end{array}$ & $\begin{array}{c}\text { Vazão } \\
\text { de Pico } \\
\left(\mathrm{m}^{3} / \mathrm{s}\right)\end{array}$ & $\begin{array}{c}\text { Vol. } \\
\text { Escoado } \\
\left(\mathrm{m}^{3}\right)\end{array}$ & $\begin{array}{c}\text { Vazão } \\
\text { de Pico } \\
\left(\mathrm{m}^{3} / \mathrm{s}\right)\end{array}$ & $\begin{array}{c}\text { Vol. } \\
\text { Escoado } \\
\left(\mathrm{m}^{3}\right)\end{array}$ \\
\hline \multirow{3}{*}{$\begin{array}{l}\text { Período de } \\
\text { retorno } \\
\text { (anos) }\end{array}$} & 2 & 2.51 & 340.1 & 4.05 & 1907.4 & 3.41 & 2631.4 & 2.34 & 3426.3 & 0.05 & 6782.6 & 0.03 & 8018.4 \\
\hline & 5 & 2.90 & 392.3 & 4.67 & 2236.9 & 3.97 & 3097.1 & 2.75 & 4039.0 & 0.06 & 7990.7 & 0.04 & 9438.4 \\
\hline & 10 & 3.23 & 437.1 & 5.22 & 2527.0 & 4.46 & 3506.1 & 3.10 & 4575.5 & 0.07 & 9040.5 & 0.04 & 10670.0 \\
\hline
\end{tabular}


Tabela A3 - Resultados da configuração 3 para condição de umidade I.

\begin{tabular}{|c|c|c|c|c|c|c|c|c|c|c|c|c|c|}
\hline \multicolumn{14}{|c|}{ Configuração 3} \\
\hline & & \multicolumn{12}{|c|}{ Tempo de Duração } \\
\hline & & \multicolumn{2}{|c|}{ tc $=1,72$} & \multicolumn{2}{|c|}{$15 \mathrm{~min}}$. & \multicolumn{2}{|c|}{$30 \mathrm{~min}}$. & \multicolumn{2}{|c|}{$60 \mathrm{~min}}$. & \multicolumn{2}{|c|}{12 horas } & \multicolumn{2}{|c|}{24 horas } \\
\hline & & $\begin{array}{c}\text { Vazão } \\
\text { de Pico } \\
\left(\mathrm{m}^{3} / \mathrm{s}\right)\end{array}$ & $\begin{array}{c}\text { Vol. } \\
\text { Escoado } \\
\left(\mathrm{m}^{3}\right) \\
\end{array}$ & $\begin{array}{c}\text { Vazão } \\
\text { de Pico } \\
\left(\mathrm{m}^{3} / \mathrm{s}\right)\end{array}$ & $\begin{array}{c}\text { Vol. } \\
\text { Escoado } \\
\left(\mathrm{m}^{3}\right)\end{array}$ & $\begin{array}{c}\text { Vazão } \\
\text { de Pico } \\
\left(\mathrm{m}^{3} / \mathrm{s}\right)\end{array}$ & $\begin{array}{c}\text { Vol. } \\
\text { Escoado } \\
\left(\mathrm{m}^{3}\right) \\
\end{array}$ & $\begin{array}{c}\text { Vazão } \\
\text { de Pico } \\
\left(\mathrm{m}^{3} / \mathrm{s}\right)\end{array}$ & \begin{tabular}{|c|} 
Vol. \\
Escoado \\
$\left(\mathrm{m}^{3}\right)$ \\
\end{tabular} & $\begin{array}{c}\text { Vazão } \\
\text { de Pico } \\
\left(\mathrm{m}^{3} / \mathrm{s}\right)\end{array}$ & \begin{tabular}{|c|} 
Vol. \\
Escoado \\
$\left(\mathrm{m}^{3}\right)$ \\
\end{tabular} & $\begin{array}{c}\text { Vazão } \\
\text { de Pico } \\
\left(\mathrm{m}^{3} / \mathrm{s}\right)\end{array}$ & $\begin{array}{c}\text { Vol. } \\
\text { Escoado } \\
\left(\mathrm{m}^{3}\right)\end{array}$ \\
\hline \multirow{3}{*}{$\begin{array}{c}\text { Período de } \\
\text { retorno } \\
\text { (anos) }\end{array}$} & 2 & 1.58 & 255.0 & 2.44 & \begin{tabular}{|l|}
1264.4 \\
\end{tabular} & 2.12 & 1825.5 & 1.52 & \begin{tabular}{|l|}
2476.9 \\
\end{tabular} & 0.26 & 5449.8 & 0.03 & 6592.1 \\
\hline & 5 & 1.82 & 294.2 & 2.82 & 1514.9 & 2.49 & 2204.2 & 1.82 & 2997.7 & 0.31 & 6565.8 & 0.03 & 7922.4 \\
\hline & 10 & 2.03 & 327.8 & 3.15 & 1742.3 & 2.82 & 2545.3 & 2.09 & 3463.6 & 0.36 & 7547.3 & 0.04 & 9088.2 \\
\hline
\end{tabular}

Tabela A4 - Resultados da configuração 4 para condição de umidade I.

\begin{tabular}{|c|c|c|c|c|c|c|c|c|c|c|c|c|c|}
\hline \multicolumn{14}{|c|}{ Configuração 4} \\
\hline & & \multicolumn{12}{|c|}{ Tempo de Duração } \\
\hline & & \multicolumn{2}{|c|}{ tc $=1,99$} & \multicolumn{2}{|c|}{$15 \mathrm{~min}}$. & \multicolumn{2}{|c|}{$30 \mathrm{~min}}$. & \multicolumn{2}{|c|}{$60 \mathrm{~min}}$. & \multicolumn{2}{|c|}{12 horas } & \multicolumn{2}{|c|}{24 horas } \\
\hline & & $\begin{array}{c}\text { Vazão } \\
\text { de Pico } \\
\left(\mathrm{m}^{3} / \mathrm{s}\right)\end{array}$ & $\begin{array}{c}\text { Vol. } \\
\text { Escoado } \\
\left(\mathrm{m}^{3}\right)\end{array}$ & $\begin{array}{c}\text { Vazão } \\
\text { de Pico } \\
\left(\mathrm{m}^{3} / \mathrm{s}\right)\end{array}$ & $\begin{array}{c}\text { Vol. } \\
\text { Escoado } \\
\left(\mathrm{m}^{3}\right)\end{array}$ & $\begin{array}{c}\text { Vazão } \\
\text { de Pico } \\
\left(\mathrm{m}^{3} / \mathrm{s}\right)\end{array}$ & $\begin{array}{c}\text { Vol. } \\
\text { Escoado } \\
\left(\mathrm{m}^{3}\right)\end{array}$ & $\begin{array}{c}\text { Vazão } \\
\text { de Pico } \\
\left(\mathrm{m}^{3} / \mathrm{s}\right)\end{array}$ & $\begin{array}{c}\text { Vol. } \\
\text { Escoado } \\
\left(\mathrm{m}^{3}\right) \\
\end{array}$ & $\begin{array}{c}\text { Vazão } \\
\text { de Pico } \\
\left(\mathrm{m}^{3} / \mathrm{s}\right)\end{array}$ & \begin{tabular}{|c|} 
Vol. \\
Escoado \\
$\left(\mathrm{m}^{3}\right)$ \\
\end{tabular} & $\begin{array}{c}\text { Vazão } \\
\text { de Pico } \\
\left(\mathrm{m}^{3} / \mathrm{s}\right)\end{array}$ & $\begin{array}{c}\text { Vol. } \\
\text { Escoado } \\
\left(\mathrm{m}^{3}\right) \\
\end{array}$ \\
\hline \multirow{3}{*}{$\begin{array}{c}\text { Período de } \\
\text { retorno } \\
\text { (anos) }\end{array}$} & 2 & 0.87 & 162.5 & 1.29 & 663.5 & 1.14 & \begin{tabular}{|l|l|}
951.4 \\
\end{tabular} & 0.81 & 1334.9 & 0.13 & \begin{tabular}{|l|}
3442.1 \\
\end{tabular} & 0.02 & 4337.9 \\
\hline & 5 & 1.00 & 187.4 & 1.48 & 785.6 & 1.32 & 1170.0 & 0.94 & 1669.1 & 0.17 & 4316.9 & 0.03 & 5419.0 \\
\hline & 10 & 1.12 & 208.8 & 1.65 & 905.6 & 1.47 & 1379.2 & 1.06 & 1983.4 & 0.20 & 5110.7 & 0.03 & 6393.0 \\
\hline
\end{tabular}

Tabela A5 - Resultados da configuração 1 para condição de umidade II.

\begin{tabular}{|c|c|c|c|c|c|c|c|c|c|c|c|c|c|}
\hline \multicolumn{14}{|c|}{ Configuração 1} \\
\hline & & \multicolumn{12}{|c|}{ Tempo de Duração } \\
\hline & & \multicolumn{2}{|c|}{$\mathrm{tc}=1,43 \mathrm{~min}}$. & \multicolumn{2}{|c|}{$15 \mathrm{~min}}$. & \multicolumn{2}{|c|}{$30 \mathrm{~min}}$. & \multicolumn{2}{|c|}{$60 \mathrm{~min}}$. & \multicolumn{2}{|c|}{12 horas } & \multicolumn{2}{|c|}{24 horas } \\
\hline & & $\begin{array}{c}\text { Vazão } \\
\text { de Pico } \\
\left(\mathrm{m}^{3} / \mathrm{s}\right)\end{array}$ & \begin{tabular}{|c} 
Vol. \\
Escoado \\
$\left(\mathrm{m}^{3}\right)$
\end{tabular} & $\begin{array}{l}\text { Vazão } \\
\text { de Pico } \\
\left(\mathrm{m}^{3} / \mathrm{s}\right)\end{array}$ & \begin{tabular}{|c|} 
Vol. \\
Escoado \\
$\left(\mathrm{m}^{3}\right)$
\end{tabular} & $\begin{array}{c}\text { Vazão } \\
\text { de Pico } \\
\left(\mathrm{m}^{3} / \mathrm{s}\right)\end{array}$ & \begin{tabular}{|c|} 
Vol. \\
Escoado \\
$\left(\mathrm{m}^{3}\right)$
\end{tabular} & $\begin{array}{c}\text { Vazão } \\
\text { de Pico } \\
\left(\mathrm{m}^{3} / \mathrm{s}\right)\end{array}$ & $\begin{array}{c}\text { Vol. } \\
\text { Escoado } \\
\left(\mathrm{m}^{3}\right)\end{array}$ & $\begin{array}{c}\text { Vazão } \\
\text { de Pico } \\
\left(\mathrm{m}^{3} / \mathrm{s}\right)\end{array}$ & $\begin{array}{c}\text { Vol. } \\
\text { Escoado } \\
\left(\mathrm{m}^{3}\right)\end{array}$ & $\begin{array}{c}\text { Vazão } \\
\text { de Pico } \\
\left(\mathrm{m}^{3} / \mathrm{s}\right)\end{array}$ & $\begin{array}{c}\text { Vol. } \\
\text { Escoado } \\
\left(\mathrm{m}^{3}\right)\end{array}$ \\
\hline \multirow{3}{*}{$\begin{array}{l}\text { Período de } \\
\text { retorno } \\
\text { (anos) }\end{array}$} & 2 & 3.24 & 410.2 & 5.54 & 2563.4 & 4.68 & 3476.5 & 3.18 & 4433.8 & 0.06 & 8232.2 & 0.04 & 9574.9 \\
\hline & 5 & 3.74 & 474.5 & 6.45 & 2983.3 & 5.45 & 4043.0 & 3.70 & 5152.2 & 0.07 & 9545.3 & 0.04 & 11096.6 \\
\hline & 10 & 4.18 & 530.2 & 7.23 & 3345.4 & 6.11 & 4530.6 & 4.15 & 5770.0 & 0.07 & 10672.6 & 0.05 & 12402.6 \\
\hline
\end{tabular}

Tabela A6 - Resultados da configuração 2 para condição de umidade II.

\begin{tabular}{|c|c|c|c|c|c|c|c|c|c|c|c|c|c|}
\hline \multicolumn{14}{|c|}{ Configuração 2} \\
\hline & & \multicolumn{12}{|c|}{ Tempo de Duração } \\
\hline & & \multicolumn{2}{|c|}{ tc $=1,53$} & \multicolumn{2}{|c|}{$15 \mathrm{~min}}$. & \multicolumn{2}{|c|}{$30 \mathrm{~min}}$. & \multicolumn{2}{|c|}{$60 \mathrm{~min}}$. & \multicolumn{2}{|c|}{12 horas } & \multicolumn{2}{|c|}{24 horas } \\
\hline & & $\begin{array}{c}\text { Vazão } \\
\text { de Pico } \\
\left(\mathrm{m}^{3} / \mathrm{s}\right)\end{array}$ & \begin{tabular}{|c|} 
Vol. \\
Escoado \\
$\left(\mathrm{m}^{3}\right)$ \\
\end{tabular} & $\begin{array}{c}\text { Vazão } \\
\text { de Pico } \\
\left(\mathrm{m}^{3} / \mathrm{s}\right)\end{array}$ & \begin{tabular}{|c|} 
Vol. \\
Escoado \\
$\left(\mathrm{m}^{3}\right)$ \\
\end{tabular} & $\begin{array}{c}\text { Vazão } \\
\text { de Pico } \\
\left(\mathrm{m}^{3} / \mathrm{s}\right)\end{array}$ & $\begin{array}{c}\text { Vol. } \\
\text { Escoado } \\
\left(\mathrm{m}^{3}\right) \\
\end{array}$ & $\begin{array}{c}\text { Vazão } \\
\text { de Pico } \\
\left(\mathrm{m}^{3} / \mathrm{s}\right)\end{array}$ & \begin{tabular}{|c|} 
Vol. \\
Escoado \\
$\left(\mathrm{m}^{3}\right)$ \\
\end{tabular} & $\begin{array}{c}\text { Vazão } \\
\text { de Pico } \\
\left(\mathrm{m}^{3} / \mathrm{s}\right)\end{array}$ & $\begin{array}{c}\text { Vol. } \\
\text { Escoado } \\
\left(\mathrm{m}^{3}\right)\end{array}$ & $\begin{array}{c}\text { Vazão } \\
\text { de Pico } \\
\left(\mathrm{m}^{3} / \mathrm{s}\right)\end{array}$ & \begin{tabular}{|c} 
Vol. \\
Escoado \\
$\left(\mathrm{m}^{3}\right)$ \\
\end{tabular} \\
\hline \multirow{3}{*}{$\begin{array}{c}\text { Período de } \\
\text { retorno } \\
\text { (anos) }\end{array}$} & 2 & 2.51 & 340.1 & 4.17 & 2090.5 & 3.64 & 2910.4 & 2.57 & 3796.2 & 0.05 & 7423.3 & 0.03 & \begin{tabular}{|l|}
8729.4 \\
\end{tabular} \\
\hline & 5 & 2.90 & 392.3 & 4.88 & 2465.3 & 4.28 & 3431.0 & 3.03 & 4470.2 & 0.06 & 8699.9 & 0.04 & 10217.3 \\
\hline & 10 & 3.23 & 437.1 & 5.50 & 2793.0 & 4.85 & 3884.3 & 3.44 & 5055.2 & 0.07 & 9801.3 & 0.04 & 11499.4 \\
\hline
\end{tabular}

Tabela A7 - Resultados da configuração 3 para condição de umidade II.

\begin{tabular}{|c|c|c|c|c|c|c|c|c|c|c|c|c|c|}
\hline \multicolumn{14}{|c|}{ Configuração 3} \\
\hline & & \multicolumn{12}{|c|}{ Tempo de Duração } \\
\hline & & \multicolumn{2}{|c|}{ tc $=1,72$} & \multicolumn{2}{|c|}{$15 \mathrm{~min}}$. & \multicolumn{2}{|c|}{$30 \mathrm{~min}}$. & \multicolumn{2}{|c|}{$60 \mathrm{~min}}$. & \multicolumn{2}{|c|}{12 horas } & \multicolumn{2}{|c|}{24 horas } \\
\hline & & $\begin{array}{c}\text { Vazão } \\
\text { de Pico } \\
\left(\mathrm{m}^{3} / \mathrm{s}\right)\end{array}$ & $\begin{array}{c}\text { Vol. } \\
\text { Escoado } \\
\left(\mathrm{m}^{3}\right)\end{array}$ & $\begin{array}{c}\text { Vazão } \\
\text { de Pico } \\
\left(\mathrm{m}^{3} / \mathrm{s}\right)\end{array}$ & $\begin{array}{c}\text { Vol. } \\
\text { Escoado } \\
\left(\mathrm{m}^{3}\right)\end{array}$ & $\begin{array}{c}\text { Vazão } \\
\text { de Pico } \\
\left(\mathrm{m}^{3} / \mathrm{s}\right)\end{array}$ & $\begin{array}{c}\text { Vol. } \\
\text { Escoado } \\
\left(\mathrm{m}^{3}\right)\end{array}$ & $\begin{array}{c}\text { Vazão } \\
\text { de Pico } \\
\left(\mathrm{m}^{3} / \mathrm{s}\right)\end{array}$ & $\begin{array}{c}\text { Vol. } \\
\text { Escoado } \\
\left(\mathrm{m}^{3}\right)\end{array}$ & $\begin{array}{c}\text { Vazão } \\
\text { de Pico } \\
\left(\mathrm{m}^{3} / \mathrm{s}\right)\end{array}$ & $\begin{array}{c}\text { Vol. } \\
\text { Escoado } \\
\left(\mathrm{m}^{3}\right)\end{array}$ & $\begin{array}{c}\text { Vazão } \\
\text { de Pico } \\
\left(\mathrm{m}^{3} / \mathrm{s}\right)\end{array}$ & $\begin{array}{c}\text { Vol. } \\
\text { Escoado } \\
\left(\mathrm{m}^{3}\right)\end{array}$ \\
\hline \multirow{3}{*}{$\begin{array}{l}\text { Período de } \\
\text { retorno } \\
\text { (anos) }\end{array}$} & 2 & 1.58 & 255.0 & 2.89 & 1601.1 & 2.50 & 2343.1 & 1.92 & 3166.3 & 0.33 & 6657.3 & 0.03 & 7935.2 \\
\hline & 5 & 1.82 & 294.2 & 3.53 & 1937.0 & 3.02 & 2825.6 & 2.33 & 3803.7 & 0.39 & 7905.6 & 0.04 & 9397.0 \\
\hline & 10 & 2.03 & 328.8 & 4.10 & 2235.3 & 3.49 & 3250.8 & 2.70 & 4362.2 & 0.50 & 8986.9 & 0.04 & 10660.8 \\
\hline
\end{tabular}


Tabela A8 - Resultados da configuração 4 para condição de umidade II.

\begin{tabular}{|c|c|c|c|c|c|c|c|c|c|c|c|c|c|}
\hline \multicolumn{14}{|c|}{ Configuração 4} \\
\hline & & \multicolumn{12}{|c|}{ Tempo de Duração } \\
\hline & & \multicolumn{2}{|c|}{ tc $=1,99$} & \multicolumn{2}{|c|}{$15 \mathrm{~min}}$. & \multicolumn{2}{|c|}{$30 \mathrm{~min}}$. & \multicolumn{2}{|c|}{$60 \mathrm{~min}}$. & \multicolumn{2}{|c|}{12 horas } & \multicolumn{2}{|c|}{24 horas } \\
\hline & & \begin{tabular}{|c|} 
Vazão \\
de Pico \\
$\left(\mathrm{m}^{3} / \mathrm{s}\right)$ \\
\end{tabular} & \begin{tabular}{|c|} 
Vol. \\
Escoado \\
$\left(\mathrm{m}^{3}\right)$
\end{tabular} & $\begin{array}{c}\text { Vazão } \\
\text { de Pico } \\
\left(\mathrm{m}^{3} / \mathrm{s}\right) \\
\end{array}$ & \begin{tabular}{|c|} 
Vol. \\
Escoado \\
$\left(\mathrm{m}^{3}\right)$
\end{tabular} & $\begin{array}{c}\text { Vazão } \\
\text { de Pico } \\
\left(\mathrm{m}^{3} / \mathrm{s}\right)\end{array}$ & $\begin{array}{c}\text { Vol. } \\
\text { Escoado } \\
\left(\mathrm{m}^{3}\right) \\
\end{array}$ & $\begin{array}{c}\text { Vazão } \\
\text { de Pico } \\
\left(\mathrm{m}^{3} / \mathrm{s}\right) \\
\end{array}$ & \begin{tabular}{|c|} 
Vol. \\
Escoado \\
$\left(\mathrm{m}^{3}\right)$ \\
\end{tabular} & $\begin{array}{c}\text { Vazão } \\
\text { de Pico } \\
\left(\mathrm{m}^{3} / \mathrm{s}\right)\end{array}$ & $\begin{array}{c}\text { Vol. } \\
\text { Escoado } \\
\left(\mathrm{m}^{3}\right)\end{array}$ & $\begin{array}{c}\text { Vazão } \\
\text { de Pico } \\
\left(\mathrm{m}^{3} / \mathrm{s}\right) \\
\end{array}$ & $\begin{array}{c}\text { Vol. } \\
\text { Escoado } \\
\left(\mathrm{m}^{3}\right)\end{array}$ \\
\hline \multirow{3}{*}{$\begin{array}{l}\text { Período de } \\
\text { retorno } \\
\text { (anos) }\end{array}$} & 2 & \begin{tabular}{|l|}
0.87 \\
\end{tabular} & 162.5 & \begin{tabular}{|l|}
1.44 \\
\end{tabular} & 931.0 & 1.32 & 1476.6 & 1.06 & \begin{tabular}{|l|}
2124.7 \\
\end{tabular} & 0.25 & 5153.0 & 0.15 & 6319.3 \\
\hline & 5 & 1.00 & 187.4 & 1.82 & 1171.9 & 1.71 & 1853.4 & 1.33 & 2650.4 & 0.30 & 6291.8 & 0.19 & 7675.5 \\
\hline & 10 & 1.12 & 208.8 & 2.21 & 1394.5 & 2.07 & 2196.0 & 1.59 & 3123.0 & 0.36 & 7292.6 & 0.22 & 8862.5 \\
\hline
\end{tabular}

Tabela A9 - Resultados da configuração 1 para condição de umidade III.

\begin{tabular}{|c|c|c|c|c|c|c|c|c|c|c|c|c|c|}
\hline \multicolumn{14}{|c|}{ Configuração 1} \\
\hline & & \multicolumn{12}{|c|}{ Tempo de Duração } \\
\hline & & \multicolumn{2}{|c|}{$\mathrm{tc}=1,43 \mathrm{~min}}$. & \multicolumn{2}{|c|}{$15 \mathrm{~min}}$. & \multicolumn{2}{|c|}{$30 \mathrm{~min}}$. & \multicolumn{2}{|c|}{$60 \mathrm{~min}}$. & \multicolumn{2}{|c|}{12 horas } & \multicolumn{2}{|c|}{24 horas } \\
\hline & & $\begin{array}{c}\text { Vazão } \\
\text { de Pico } \\
\left(\mathrm{m}^{3} / \mathrm{s}\right)\end{array}$ & \begin{tabular}{|c|} 
Vol. \\
Escoado \\
$\left(\mathrm{m}^{3}\right)$
\end{tabular} & $\begin{array}{c}\text { Vazão } \\
\text { de Pico } \\
\left(\mathrm{m}^{3} / \mathrm{s}\right)\end{array}$ & \begin{tabular}{|c|} 
Vol. \\
Escoado \\
$\left(\mathrm{m}^{3}\right)$
\end{tabular} & $\begin{array}{c}\text { Vazão } \\
\text { de Pico } \\
\left(\mathrm{m}^{3} / \mathrm{s}\right)\end{array}$ & \begin{tabular}{|c|} 
Vol. \\
Escoado \\
$\left(\mathrm{m}^{3}\right)$
\end{tabular} & $\begin{array}{c}\text { Vazão de } \\
\text { Pico } \\
\left(\mathrm{m}^{3} / \mathrm{s}\right)\end{array}$ & $\begin{array}{c}\text { Vol. } \\
\text { Escoado } \\
\left(\mathrm{m}^{3}\right)\end{array}$ & $\begin{array}{c}\text { Vazão de } \\
\text { Pico } \\
\left(\mathrm{m}^{3} / \mathrm{s}\right)\end{array}$ & $\begin{array}{c}\text { Vol. } \\
\text { Escoado } \\
\left(\mathrm{m}^{3}\right)\end{array}$ & $\begin{array}{c}\text { Vazão de } \\
\text { Pico } \\
\left(\mathrm{m}^{3} / \mathrm{s}\right)\end{array}$ & $\begin{array}{c}\text { Vol. } \\
\text { Escoado } \\
\left(\mathrm{m}^{3}\right)\end{array}$ \\
\hline \multirow{3}{*}{$\begin{array}{l}\text { Período de } \\
\text { retorno } \\
\text { (anos) }\end{array}$} & 2 & 3.33 & 423.7 & 5.84 & 2683.3 & 4.93 & 3618.4 & 3.34 & 4592.3 & 0.06 & 8426.6 & 0.04 & 9776.8 \\
\hline & 5 & 3.87 & 493.0 & 6.79 & 3114.3 & 5.72 & 4195.3 & 3.87 & 5320.3 & 0.07 & 9746.8 & 0.04 & 11305.1 \\
\hline & 10 & 4.34 & 552.9 & 7.62 & 3484.5 & 6.41 & 4690.5 & 4.33 & 5945.1 & 0.07 & 10879.0 & 0.05 & 12615.7 \\
\hline
\end{tabular}

Tabela A10 - Resultados da configuração 2 para condição de umidade III.

\begin{tabular}{|c|c|c|c|c|c|c|c|c|c|c|c|c|c|}
\hline \multicolumn{14}{|c|}{ Configuração 2} \\
\hline & & \multicolumn{12}{|c|}{ Tempo de Duração } \\
\hline & & \multicolumn{2}{|c|}{$\mathrm{tc}=1,53$} & \multicolumn{2}{|c|}{$15 \mathrm{~min}}$. & \multicolumn{2}{|c|}{$30 \mathrm{~min}$} & \multicolumn{2}{|c|}{$60 \mathrm{~min}}$. & \multicolumn{2}{|c|}{12 horas } & \multicolumn{2}{|c|}{24 horas } \\
\hline & & $\begin{array}{c}\text { Vazão } \\
\text { de Pico } \\
\left(\mathrm{m}^{3} / \mathrm{s}\right) \\
\end{array}$ & \begin{tabular}{|c|} 
Vol. \\
Escoado \\
$\left(\mathrm{m}^{3}\right)$
\end{tabular} & $\begin{array}{c}\text { Vazão } \\
\text { de Pico } \\
\left(\mathrm{m}^{3} / \mathrm{s}\right)\end{array}$ & \begin{tabular}{|c|}
$\begin{array}{c}\text { Vol. } \\
\text { Escoado } \\
\left(\mathrm{m}^{3}\right)\end{array}$ \\
\end{tabular} & $\begin{array}{c}\text { Vazão } \\
\text { de Pico } \\
\left(\mathrm{m}^{3} / \mathrm{s}\right)\end{array}$ & \begin{tabular}{|c|}
$\begin{array}{c}\text { Vol. } \\
\text { Escoado } \\
\left(\mathrm{m}^{3}\right)\end{array}$ \\
\end{tabular} & $\begin{array}{c}\text { Vazão de } \\
\text { Pico } \\
\left(\mathrm{m}^{3} / \mathrm{s}\right)\end{array}$ & $\begin{array}{c}\text { Vol. } \\
\text { Escoado } \\
\left(\mathrm{m}^{3}\right)\end{array}$ & $\begin{array}{c}\text { Vazão de } \\
\text { Pico } \\
\left(\mathrm{m}^{3} / \mathrm{s}\right)\end{array}$ & $\begin{array}{c}\text { Vol. } \\
\text { Escoado } \\
\left(\mathrm{m}^{3}\right)\end{array}$ & $\begin{array}{c}\text { Vazão de } \\
\text { Pico } \\
\left(\mathrm{m}^{3} / \mathrm{s}\right)\end{array}$ & $\begin{array}{c}\text { Vol. } \\
\text { Escoado } \\
\left(\mathrm{m}^{3}\right)\end{array}$ \\
\hline \multirow{3}{*}{$\begin{array}{c}\text { Período de } \\
\text { retorno } \\
\text { (anos) }\end{array}$} & 2 & 2.54 & 348.1 & 4.70 & 2358.0 & 4.11 & 3254.8 & 2.91 & 4204.3 & 0.06 & 7987.2 & 0.03 & 9327.4 \\
\hline & 5 & 2.97 & 407.3 & 5.55 & 2770.6 & 4.84 & 3814.8 & 3.43 & 4917.6 & 0.06 & 9297.5 & 0.04 & 10846.7 \\
\hline & 10 & 3.35 & 459.4 & 6.28 & 3127.6 & 5.48 & 4297.9 & 3.87 & 5531.9 & 0.07 & 10422.9 & 0.04 & 12151.1 \\
\hline
\end{tabular}

Tabela A11 - Resultados da configuração 3 para condição de umidade III.

\begin{tabular}{|c|c|c|c|c|c|c|c|c|c|c|c|c|c|}
\hline \multicolumn{14}{|c|}{ Configuração 3} \\
\hline & & \multicolumn{12}{|c|}{ Tempo de Duração } \\
\hline & & \multicolumn{2}{|c|}{ tc $=1,72$} & \multicolumn{2}{|c|}{$15 \mathrm{~min}}$. & \multicolumn{2}{|c|}{$30 \mathrm{~min}}$. & \multicolumn{2}{|c|}{$60 \mathrm{~min}}$. & \multicolumn{2}{|c|}{12 horas } & \multicolumn{2}{|c|}{24 horas } \\
\hline & & $\begin{array}{c}\text { Vazão } \\
\text { de Pico } \\
\left(\mathrm{m}^{3} / \mathrm{s}\right)\end{array}$ & $\begin{array}{c}\text { Vol. } \\
\text { Escoado } \\
\left(\mathrm{m}^{3}\right)\end{array}$ & $\begin{array}{c}\text { Vazão } \\
\text { de Pico } \\
\left(\mathrm{m}^{3} / \mathrm{s}\right)\end{array}$ & $\begin{array}{c}\text { Vol. } \\
\text { Escoado } \\
\left(\mathrm{m}^{3}\right)\end{array}$ & $\begin{array}{c}\text { Vazão } \\
\text { de Pico } \\
\left(\mathrm{m}^{3} / \mathrm{s}\right)\end{array}$ & $\begin{array}{c}\text { Vol. } \\
\text { Escoado } \\
\left(\mathrm{m}^{3}\right)\end{array}$ & $\begin{array}{c}\text { Vazão de } \\
\text { Pico } \\
\left(\mathrm{m}^{3} / \mathrm{s}\right)\end{array}$ & $\begin{array}{c}\text { Vol. } \\
\text { Escoado } \\
\left(\mathrm{m}^{3}\right)\end{array}$ & $\begin{array}{c}\text { Vazão de } \\
\text { Pico } \\
\left(\mathrm{m}^{3} / \mathrm{s}\right)\end{array}$ & $\begin{array}{c}\text { Vol. } \\
\text { Escoado } \\
\left(\mathrm{m}^{3}\right)\end{array}$ & $\begin{array}{c}\text { Vazão de } \\
\text { Pico } \\
\left(\mathrm{m}^{3} / \mathrm{s}\right)\end{array}$ & $\begin{array}{c}\text { Vol. } \\
\text { Escoado } \\
\left(\mathrm{m}^{3}\right)\end{array}$ \\
\hline \multirow{3}{*}{$\begin{array}{l}\text { Período de } \\
\text { retorno } \\
\text { (anos) }\end{array}$} & 2 & 2.08 & 349.2 & 4.60 & 2348.5 & 3.89 & 3263.7 & 2.88 & 4225.7 & 0.51 & 8043.2 & 0.03 & 9389.8 \\
\hline & 5 & 2.52 & 422.4 & 5.46 & 2770.3 & 4.62 & 3832.6 & 3.41 & 4947.0 & 0.06 & 9359.9 & 0.04 & 10914.9 \\
\hline & 10 & 2.91 & 487.3 & 6.19 & 3134.2 & 5.26 & 4322.3 & 3.86 & 5567.0 & 0.07 & 10489.8 & 0.04 & 12223.3 \\
\hline
\end{tabular}

Tabela A12 - Resultados da configuração 4 para condição de umidade III.

\begin{tabular}{|c|c|c|c|c|c|c|c|c|c|c|c|c|c|}
\hline \multicolumn{14}{|c|}{ Configuração 4} \\
\hline & & \multicolumn{12}{|c|}{ Tempo de Duração } \\
\hline & & \multicolumn{2}{|c|}{ tc $=1,99$} & \multicolumn{2}{|c|}{$15 \mathrm{~min}}$. & \multicolumn{2}{|c|}{$30 \mathrm{~min}$. } & \multicolumn{2}{|c|}{$60 \mathrm{~min}}$. & \multicolumn{2}{|c|}{12 horas } & \multicolumn{2}{|c|}{24 horas } \\
\hline & & $\begin{array}{c}\text { Vazão } \\
\text { de Pico } \\
\left(\mathrm{m}^{3} / \mathrm{s}\right)\end{array}$ & $\begin{array}{c}\text { Vol. } \\
\text { Escoado } \\
\left(\mathrm{m}^{3}\right)\end{array}$ & $\begin{array}{c}\text { Vazão } \\
\text { de Pico } \\
\left(\mathrm{m}^{3} / \mathrm{s}\right)\end{array}$ & $\begin{array}{c}\text { Vol. } \\
\text { Escoado } \\
\left(\mathrm{m}^{3}\right)\end{array}$ & $\begin{array}{c}\text { Vazão } \\
\text { de Pico } \\
\left(\mathrm{m}^{3} / \mathrm{s}\right)\end{array}$ & $\begin{array}{c}\text { Vol. } \\
\text { Escoado } \\
\left(\mathrm{m}^{3}\right)\end{array}$ & $\begin{array}{c}\text { Vazão de } \\
\text { Pico } \\
\left(\mathrm{m}^{3} / \mathrm{s}\right)\end{array}$ & $\begin{array}{c}\text { Vol. } \\
\text { Escoado } \\
\left(\mathrm{m}^{3}\right)\end{array}$ & \begin{tabular}{|c|} 
Vazão de \\
Pico \\
$\left(\mathrm{m}^{3} / \mathrm{s}\right)$
\end{tabular} & $\begin{array}{c}\text { Vol. } \\
\text { Escoado } \\
\left(\mathrm{m}^{3}\right)\end{array}$ & $\begin{array}{c}\text { Vazão de } \\
\text { Pico } \\
\left(\mathrm{m}^{3} / \mathrm{s}\right)\end{array}$ & $\begin{array}{c}\text { Vol. } \\
\text { Escoado } \\
\left(\mathrm{m}^{3}\right)\end{array}$ \\
\hline \multirow{3}{*}{$\begin{array}{l}\text { Período de } \\
\text { retorno } \\
\text { (anos) }\end{array}$} & 2 & 0.94 & 187.9 & 2.75 & 1612.4 & 2.51 & 2415.2 & 1.89 & 3289.9 & 0.38 & 6932.0 & 0.23 & 8244.3 \\
\hline & 5 & 1.16 & 233.8 & 3.42 & 1977.3 & 3.07 & 2931.2 & 2.33 & 3962.1 & 0.47 & 8213.9 & 0.28 & 9738.2 \\
\hline & 10 & 1.37 & 277.2 & 4.03 & 2299.3 & 3.57 & 3382.5 & 2.71 & 4547.0 & 0.54 & 9319.7 & 0.32 & 11025.1 \\
\hline
\end{tabular}




\section{APÊNDICE B - Resultados de eficiência hidrológica com relação à configuração atual.}

Tabela B1 - Eficiência da configuração 2 na condição de umidade I.

\begin{tabular}{|cccccccc|}
\hline \multicolumn{7}{|c|}{ Eficiência da Configuração 2 (\%) } \\
\hline & & tc & 15 min. & 30 min. & 60 min. & 12 horas & 24 horas \\
\hline & 2 & 17,04 & 22,41 & 21,14 & 19,66 & 15,09 & 13,91 \\
\hline $\begin{array}{c}\text { Periodo de } \\
\text { retorno } \\
\text { (anos) }\end{array}$ & 5 & 17,04 & 21,82 & 20,28 & 18,64 & 13,94 & 12,77 \\
\cline { 2 - 8 } & 10 & 17,04 & 21,28 & 19,56 & 17,83 & 13,07 & 11,92 \\
\hline
\end{tabular}

Tabela B2 - Eficiência da configuração 3 na condição de umidade I.

\begin{tabular}{|cccccccc|}
\hline \multicolumn{7}{|c|}{ Eficiência da Configuração 3 (\%) } \\
\hline & \multicolumn{8}{c|}{ Tempo de Duração } \\
\hline \multirow{2}{*}{$\begin{array}{c}\text { Período de } \\
\text { retorno } \\
\text { (anos) }\end{array}$} & 2 & tc & 15 min. & 30 min. & 60 min. & 12 horas & 24 horas \\
\cline { 2 - 9 } & 10 & 37,79 & 48,57 & 45,29 & 41,92 & 31,78 & 29,22 \\
\hline
\end{tabular}

Tabela B3 - Eficiência da configuração 4 na condição de umidade I.

\begin{tabular}{|c|c|c|c|c|c|c|c|}
\hline \multicolumn{8}{|c|}{ Eficiência da Configuração 4 (\%) } \\
\hline & & \multicolumn{6}{|c|}{ Tempo de Duração } \\
\hline & & tc & $15 \mathrm{~min}$. & $30 \mathrm{~min}$. & $60 \mathrm{~min}$. & 12 horas & 24 horas \\
\hline \multirow{3}{*}{$\begin{array}{l}\text { Período de } \\
\text { retorno } \\
\text { (anos) }\end{array}$} & 2 & 60,37 & 73,01 & 71,49 & 68,70 & 56,91 & 53,43 \\
\hline & 5 & 60,37 & 72,55 & 69,88 & 66,38 & 53,50 & 49,92 \\
\hline & 10 & 60,37 & 71,79 & 68,36 & 64,38 & 50,86 & 47,23 \\
\hline
\end{tabular}

Tabela B4 - Eficiência da configuração 2 na condição de umidade II.

\begin{tabular}{|cccccccc|}
\hline \multicolumn{7}{|c|}{ Eficiência da Configuração 2 (\%) } \\
\cline { 2 - 8 } & & tc & 15 min. & 30 min. & 60 min. & 12 horas & 24 horas \\
\hline $\begin{array}{c}\text { Periodo de } \\
\text { retorno } \\
\text { (anos) }\end{array}$ & 2 & 17,10 & 18,45 & 16,28 & 14,38 & 9,83 & 8,83 \\
\cline { 2 - 8 } & 10 & 17,32 & 17,36 & 15,14 & 13,24 & 8,86 & 7,92 \\
\hline
\end{tabular}

Tabela B5 - Eficiência da configuração 3 na condição de umidade II.

\begin{tabular}{|c|c|c|c|c|c|c|c|}
\hline \multicolumn{8}{|c|}{ Eficiência da Configuração $3(\%)$} \\
\hline \multirow{5}{*}{$\begin{array}{l}\text { Período de } \\
\text { retorno } \\
\text { (anos) }\end{array}$} & & \multicolumn{6}{|c|}{ Tempo de Duração } \\
\hline & & tc & $15 \mathrm{~min}$. & $30 \mathrm{~min}$. & $60 \mathrm{~min}$. & 12 horas & 24 horas \\
\hline & 2 & 37,84 & 37,54 & 32,60 & 28,59 & 19,13 & 17,13 \\
\hline & 5 & 38,01 & 35,07 & 30,11 & 26,17 & 17,18 & 15,32 \\
\hline & 10 & 37,99 & 33,18 & 28,25 & 24,40 & 15,79 & 14,04 \\
\hline
\end{tabular}

Tabela B6 - Eficiência da configuração 4 na condição de umidade II.

\begin{tabular}{|c|c|c|c|c|c|c|c|}
\hline \multicolumn{8}{|c|}{ Eficiência da Configuração 4 (\%) } \\
\hline \multirow{5}{*}{$\begin{array}{l}\text { Período de } \\
\text { retorno } \\
\text { (anos) }\end{array}$} & & \multicolumn{6}{|c|}{ Tempo de Duração } \\
\hline & & tc & $15 \mathrm{~min}$. & $30 \mathrm{~min}$. & $60 \mathrm{~min}$. & 12 horas & 24 horas \\
\hline & 2 & 60,40 & 63,68 & 57,53 & 52,08 & 37,40 & 34,00 \\
\hline & 5 & 60,50 & 60,72 & 54,16 & 48,56 & 34,09 & 30,83 \\
\hline & 10 & 60,62 & 58,32 & 51,53 & 45,88 & 31,67 & 28,54 \\
\hline
\end{tabular}


Tabela B7 - Eficiência da configuração 2 na condição de umidade III.

\begin{tabular}{|cccccccc|}
\hline \multicolumn{7}{|c|}{ Eficiência da Configuração 2 (\%) } \\
\hline & & tc & 15 min. & 30 min. & 60 min. & 12 horas & 24 horas \\
\hline $\begin{array}{c}\text { Período de } \\
\text { retorno } \\
\text { (anos) }\end{array}$ & 2 & 17,84 & 12,12 & 10,05 & 8,45 & 5,21 & 4,60 \\
\cline { 2 - 9 } & 5 & 17,37 & 11,03 & 9,07 & 7,57 & 4,61 & 4,05 \\
\hline
\end{tabular}

Tabela B8 - Eficiência da configuração 3 na condição de umidade III.

\begin{tabular}{|c|c|c|c|c|c|c|c|}
\hline \multicolumn{8}{|c|}{ Eficiência da Configuração 3 (\%) } \\
\hline & & \multicolumn{6}{|c|}{ Tempo de Duração } \\
\hline & & tc & $15 \mathrm{~min}$. & $30 \mathrm{~min}$. & $60 \mathrm{~min}$. & 12 horas & 24 horas \\
\hline \multirow{3}{*}{$\begin{array}{l}\text { Período de } \\
\text { retorno } \\
\text { (anos) }\end{array}$} & 2 & 17,59 & 12,48 & 9,80 & 7,98 & 4,55 & 3,96 \\
\hline & 5 & 14,32 & 11,04 & 8,65 & 7,02 & 3,97 & 3,45 \\
\hline & 10 & 11,86 & 10,05 & 7,85 & 6,36 & 3,58 & 3,11 \\
\hline
\end{tabular}

Tabela B9 - Eficiência da configuração 4 na condição de umidade III.

\begin{tabular}{|cccccccc|}
\hline \multicolumn{7}{|c|}{ Eficiência da Configuração 4 (\%) } \\
\cline { 2 - 8 } & & tc & 15 min. & 30 min. & 60 min. & 12 horas & 24 horas \\
\hline $\begin{array}{c}\text { Periodo de } \\
\text { retorno } \\
\text { (anos) }\end{array}$ & 2 & 55,65 & 39,91 & 33,25 & 28,36 & 17,74 & 15,67 \\
\cline { 2 - 8 } & 10 & 52,57 & 36,51 & 30,13 & 25,53 & 15,73 & 13,86 \\
\hline
\end{tabular}

\section{APÊNDICE C - Gráficos de dispersão da eficiência em função da precipitação}
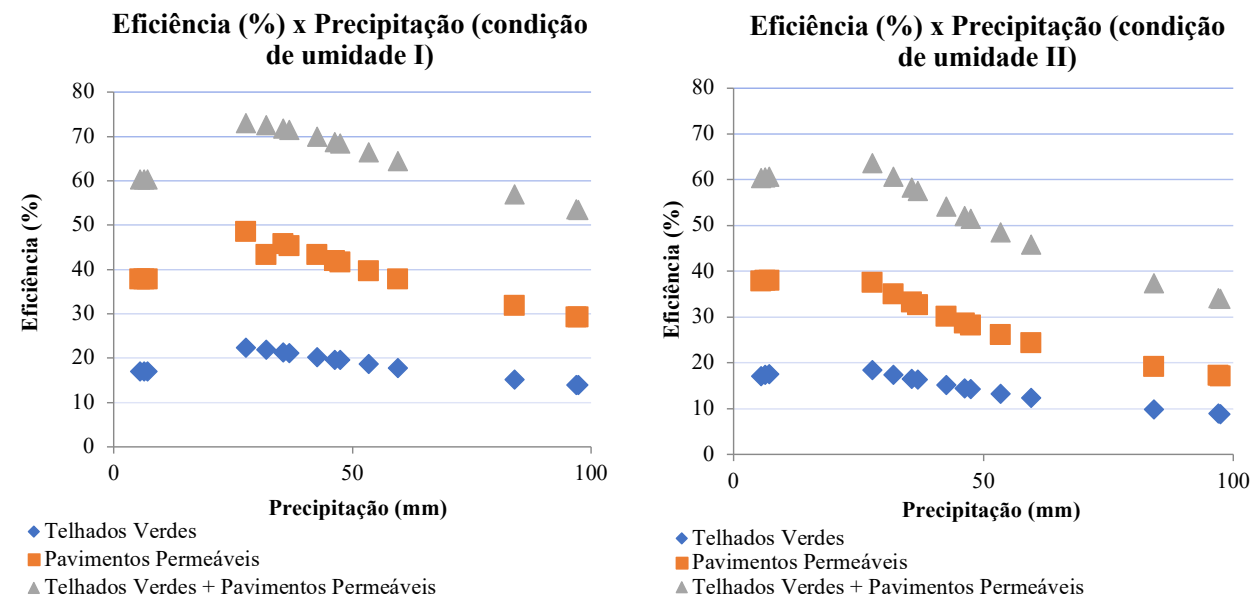

Eficiência (\%) x Precipitação (condição de umidade

III)

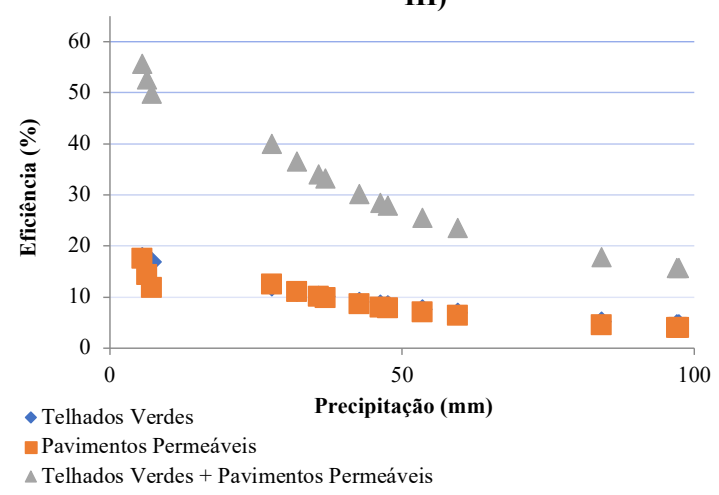

